San Jose State University

SJSU ScholarWorks

Master's Theses

Master's Theses and Graduate Research

Summer 2013

\title{
Effects of White Space on Consumer Perceptions of Value in E- Commerce
}

Sin Lee Loh

San Jose State University

Follow this and additional works at: https://scholarworks.sjsu.edu/etd_theses

\section{Recommended Citation}

Loh, Sin Lee, "Effects of White Space on Consumer Perceptions of Value in E-Commerce" (2013). Master's Theses. 4351.

DOI: https://doi.org/10.31979/etd.gu7c-rcj2

https://scholarworks.sjsu.edu/etd_theses/4351

This Thesis is brought to you for free and open access by the Master's Theses and Graduate Research at SJSU ScholarWorks. It has been accepted for inclusion in Master's Theses by an authorized administrator of SJSU ScholarWorks. For more information, please contact scholarworks@sjsu.edu. 


\title{
EFFECTS OF WHITE SPACE ON CONSUMER PERCEPTIONS OF VALUE IN E-COMMERCE
}

\author{
A Thesis \\ Presented to \\ The Faculty of the Graduate Program in Human Factors and Ergonomics \\ San José State University \\ In Partial Fulfillment \\ of the Requirements for the Degree \\ Master of Science
}

by

Sin Lee Loh

August 2013 
(C) 2013

Sin Lee Loh

ALL RIGHTS RESERVED 
The Designated Thesis Committee Approves the Thesis Titled EFFECTS OF WHITE SPACE ON CONSUMER PERCEPTIONS OF VALUE IN E-COMMERCE

by

Sin Lee Loh

APPROVED FOR THE DEPARTMENT OF INDUSTRIAL AND SYSTEMS

ENGINEERING

SAN JOSÉ STATE UNIVERSITY

August 2013

Dr. Sean Laraway

Department of Psychology

Dr. Kevin Jordan

Department of Psychology

Dr. Emily Wughalter

Department of Kinesiology 


\title{
ABSTRACT \\ EFFECTS OF WHITE SPACE ON CONSUMER PERCEPTIONS OF VALUE IN E-COMMERCE
}

\author{
By Sin Lee Loh
}

As e-commerce becomes an increasingly large industry, questions remain about how the isolated effects of design elements on websites influence consumer perceptions and purchasing behavior. This study used a quantitative approach to measuring the effect of a ubiquitous element of design, white space, on the perception of the monetary value of individual items. White space is a key component of design and website usability, yet it has been shown to be related to the perception of luxury. Little is known about the direct relationship between manipulation of white space and the outcomes on consumer perceptions of value in an e-commerce context. This study found no significant difference between two levels of total white space area (large vs. small) measured by participants' perceived cost of items (chairs). In contrast, while holding total white space constant, the effect of white space distance between images was significant for males but not for females. Additionally, no significant relationship between gender and frequency of online shopping behavior was found, $\chi^{2}(1)=3.19, p=.07, \phi=.17$. Gender and amount of time spent per month online were significantly related, $\chi^{2}(1)=6.21, p=.013$, $\phi=.24$ 


\section{ACKNOWLEDGEMENTS}

I would like to sincerely thank my thesis committee for their support, guidance and incredible patience throughout the process of completing this thesis. I owe a great deal of appreciation to Dr. Kevin Jordan and Dr. Emily Wughalter for their attention to detail and their willingness to challlege me intellectually. My deepest gratitude also goes to Dr. Sean Laraway, Chair of my thesis committee, for all his valuable insights, advice and good humor. It has been an honor and a pleasure to have worked with you.

Many thanks goes out to all the great professors who have inspired and motivated me along my academic journey. Dr. Louis Freund and Dr. Anthony Andre, in particular, for their unforgettable lectures in Human Factors \& Ergonomics. Thanks are also due to Dr. Robert Levine and Dr. Lorin Lachs at California State University, Fresno for instilling in me a passion for research.

To my parents, thank you for your endless love and tireless support through the years. I have so much respect for you both for being the most hardworking, driven and fearless people I have ever known. Thanks for always being there even when you're miles away.

To my friends and classmates, thank you for your help when I needed it and for telling me to pick myself up and keep on going whenever I whined.

Lastly, this thesis couldn't have been completed without Joe Blubaugh, who provided essential programming skills for the web program in this project and emotional support to get me through. Joe, I'm yours for life! 


\section{Table of Contents}

SECTION

PAGE

Introduction and Review of Literature ................................................................. 1

White Space in Design ..................................................................... 1

Usability and White Space.................................................................. 1

Perceived ease-of-use.................................................................4

Information density. ................................................................

The value of usability and white space..............................................

White space, trust, and credibility online ...........................................6

The Online Retail Environment and Purchasing Behavior............................ 7

White Space and Consumer Perceptions .............................................. 10

Subjective price perception .......................................................... 11

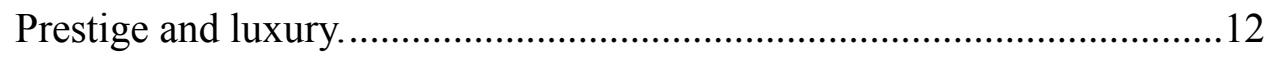

Purpose and Research Questions ......................................................... 13

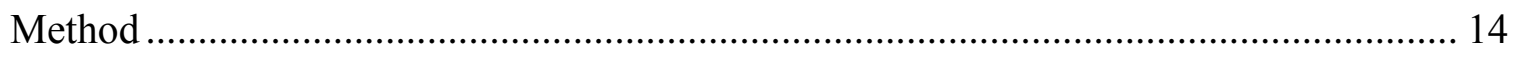

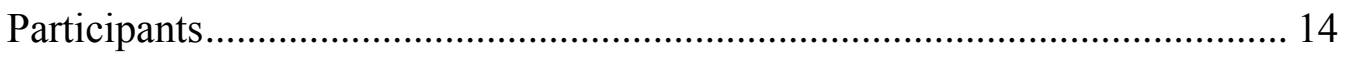

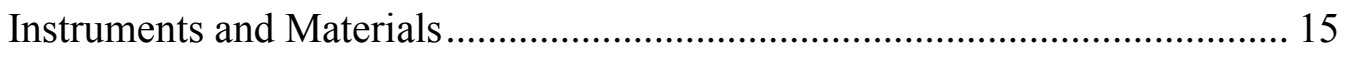

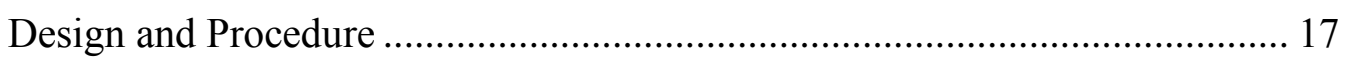

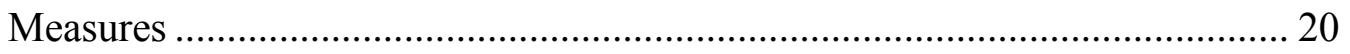




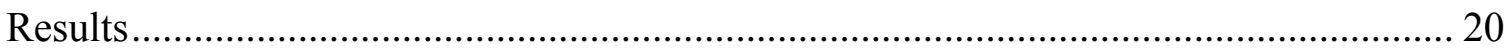

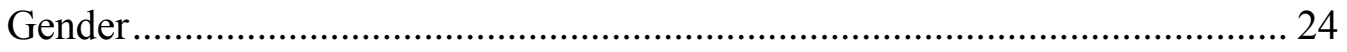

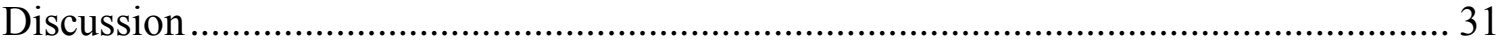

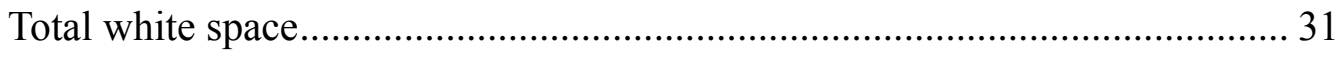

White space distance between images ............................................................ 32

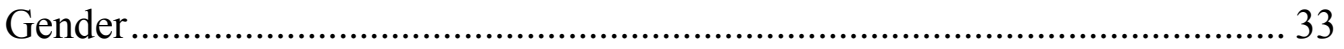

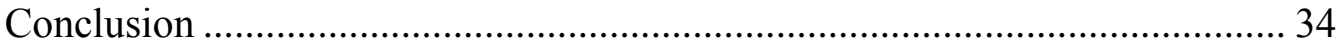

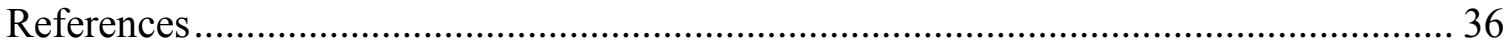

Appendix A: Samples of Retail Furniture Websites ……………………................... 45

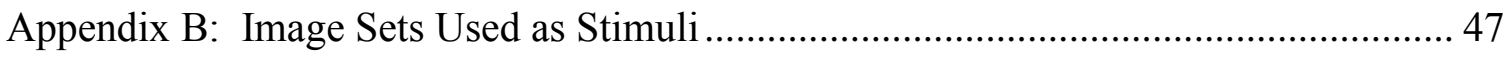

Appendix C: Stimuli at Near (40 px), Medium (80 px) and Far (120 px) Distances of

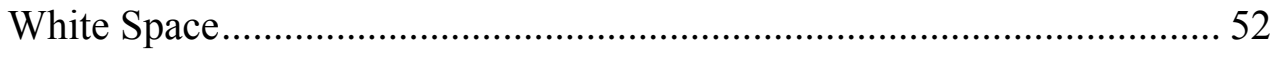

Appendix D: Demographic Questionnaire................................................................. 54

Appendix E: Agreement to Participate in Research.................................................... 55

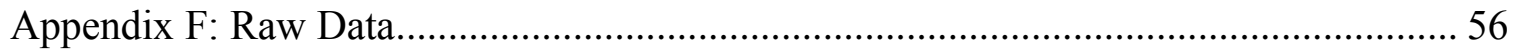

Appendix G: San José State University Institutional Review Board Approval Letter .... 60 


\section{List of Figures}

FIGURE

PAGE

Figure 1. Retail Furniture Website Created by Experimenter .......................................16

Figure 2. Instructions and Error Message on Stimuli ....................................................18

Figure 3. Sample of Total White Space Area …………............................................18

Figure 4. Graph of Estimated Mean Values by White Space Distance Between ...........23

Figure 5. Graph of Estimated Mean Values by Total White Space ………….................24

Figure 6. Graphs of Estimated Mean Values by Gender ................................................27

Figure 7. Frequency of Online Shopping by Gender .................................................28

Figure 8. Online Spending per Month by Gender ..........................................................30

Figure 9. Website of Design within Reach, Furniture Retailer.........................................45

Figure 10. Website of Overstock.com, General Retailer..................................................45

Figure 11. Website of Target, General Retailer. ..............................................................46

Figure 12. Website of Ikea, Furniture Retailer................................................................46

Figure 13. Sample Stimuli in 2-Image Condition......................................................52

Figure 14. Sample Stimuli in 3-Image Condition..........................................................53 


\section{List of Tables}

TABLE

PAGE

Table 1. Descriptive Statistics for Estimated Value (USD) by Total White Space ...........20

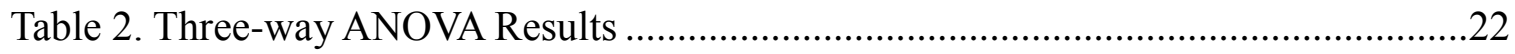

Table 3. Simple Comparisons for White Space Distance Between ................................22

Table 4. Descriptive Statistics for the Estimated Value (USD) by Gender, .....................25

Table 5. Simple Comparisons of White Space Distance between by Gender....................26

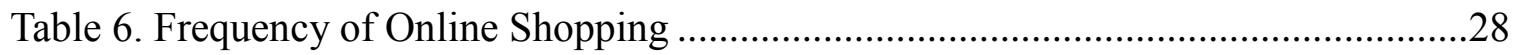

Table 7. Amount Spent per Month in Online Shopping.............................................30 


\section{Introduction and Review of Literature}

\section{White Space in Design}

"White space" is the term used in the visual arts to describe the space around subject(s) in a visual scene or composition (Finke, 2001; Robertson, 1994). White space need not necessarily be "white," because it can also be described as "negative space" that surrounds a subject or image. It therefore can be any dominant background color in a composition in which the foreground content or context is referred to as "positive space." In photography, negative spaces are used to draw attention to the foreground and aid in the depiction of scenes accurately by depicting the relationship of objects to each other (Krages, 2005). In essence, visual boundaries are formed by the relationship between white spaces and the subject in a visual scene. When used skillfully, white space acts as a directive visual signal to call attention to information (Amare \& Alan, 2013) and acts as a key element in artistic composition by defining the subjects and bringing balance to visual scenes. Among designers, use of white space is known to provide context to evoke moods (Finke, 2001) as well as to communicate symbolic meaning (Robertson, 1994). In addition to print, the concept and advantages of proper use of white space has been proposed to apply to on-screen environments in a similar manner (Ahrens \& Bovee, 1994).

\section{Usability and White Space}

On a screen interface, white space is known as the on-screen areas that do not contain text, graphics, or other visual elements (Bradshaw \& Johari, 2000). White space does not just serve an aesthetic purpose, but adds functionality as well (Bernard, 
Chaparro \& Thomasson, 2000). White space is critical for imposing structure to organize and differentiate content by providing contrast against content and text (Bradshaw \& Johari, 2002; Morgan, 1999; Parker, 1988). When effectively used in layouts, white space forms visual structure by defining relationships between elements in ways that can emphasize and draw attention to important elements (Truchard \& Katz-Haas, 1998; White, 2011). The presence of white space allows users to visually delineate content from the background and content from other content by providing a spatial boundary (sometimes referred to as "padding" in the web-design field). Good use of white space aids users in recognizing relationships between visual content and forms an essential component of usability on web interfaces in the design industry (D'angelo \& Little, 1998; Nielsen \& Gilutz, 2003; Thüring, Hannemann, \& Haake, 1995).

Usability is defined by ISO 9241-11 (1998) as the effectiveness, efficiency, and satisfaction of a system used by specific users to achieve specific goals. Presently, the general effects of white space on usability are not well understood even though white space is accepted as common good practice by the design industry. Guidelines for usability for web interfaces generally encourage the "effective use" of white space (D’angelo \& Little, 1998; Nielsen \& Gilutz, 2003; Truchard, \& Katz-Haas, 1998), although the definition of "effective use" of white space is vague at best (Cunliffe, 2000). Some studies have advocated using white space sparingly as a guideline (Spool, 1997), although there are few empirical studies demonstrating a direct link between white space usage and measurable usability outcomes. 
Clutter is a state where an excessive number of visual items detract users from efficient task performance (Rosenholtz, Mansfield \& Jin, 2005). In an analysis of design features and layouts of e-commerce websites from China and the United States, Lo and Gong (2005) found that Chinese sites tended to use less white space as they had a greater variety and density of layout elements and content. They concluded that this resulted in Chinese sites appearing "more cluttered." Designers have cautioned against "cluttered interfaces," as they are less effective at communicating (Burns, Vent \& Hansen, 1988; Felici \& Nace, 1987). Indeed, published guidelines often advocate the proper use of white space to facilitate users in readability and effective visual search (Carusso, 1986; Petterson, 1993). Reading speed, comprehension, and subjective satisfaction have been shown to be affected by manipulation of white space (Chaparro, Shaikh, \& Baker, 2005; Chaparro et al., 2004). Rau, Gao and Liu (2007) advocated designing "simple" web portals with greater use of white space because they result in greater task efficiency, fewer errors, and higher subjective satisfaction ratings than do "rich" web portals.

Why is "simpler" better? One explanation is that a large amount of content (and inversely, a small amount of total white space) can cause excessive cognitive overhead (Dalal, Quible \& Wyatt, 1999). Content competes for cognitive resources, and because human working memory is limited, excessive content places additional load on information processing and reduces the cognitive resources left for comprehension. Therefore, effective application of white space allows users to direct their cognitive resources more efficiently and effectively to task-related content. White space may also play a role in the proximity-compatibility principle in which users must mentally 
integrate information sources to perform tasks (Wickens \& Carswell, 1995). The proximity of two related elements needed to perform a task or mental operation maximizes efficiency and reduces the cognitive load required. Conversely, employing a greater distance (and therefore increasing the amount of white space) between other incompatible or irrelevant elements diverts attention away from making associations between incompatible elements. Therefore, white space may be an invisible, but integral, component in efficient task performance in an online retail context, which may contain multiple task-related elements with varying amounts of white space between elements.

Perceived ease-of-use. Interacting with a system to achieve a goal requires effort that users perceive even before they perform any actions towards their goal. The "perceived ease-of-use" therefore refers to the perceived amount of effort that users believe are required from them to carry out a task (Davis, 1989). White space is highly related to the perceived ease of use. In a comparative usability test of e-commerce websites, Smith (2008) observed that senior citizens made the most favorable comments about websites with the highest amount of white space, perceiving that greater use of white space made web seem pages "easier to understand."

Information density. Because an individual display screen size is fixed, increasing the amount (and/or size) of content results in a reduction in white space, within the same visual display. Information density is therefore the total amount of content that is displayed on a web page (Huang \& Yang, 2011). The total amount of white space on a screen cannot be manipulated without a subsequent proportional change in information density, and vice-versa. There is some debate on the effects of white space 
on usability. Some researchers have mentioned that a greater amount of white space had positive results on usability (e.g., Chaparro et al., 2004; Nielsen \& Gilutz, 2003; Ray, Gao \& Liu, 2007), while other researchers have found that poor application of white space does not impact task performance (Chaparro, Shaikh \& Baker, 2005). Spool et al. (1997) found that users perceive websites with greater amounts of white space as more difficult to read, search, and use. Spool et al. hypothesized that because users tend to visually skim instead of focus on details, high information density aids users in visual search tasks. That is, more amount of content present on the screen increases the likelihood that users will find their target amongst the content by visually scanning the page. According to Spool et al., spreading information out causes the inefficient need to scroll because task-relevant content may be located in other parts of a continuous page that does not fit in the visual space on the screen. Increasing information density has also been shown to result in greater performance without loss of accuracy or subjective satisfaction (Staggers, 1993).

The value of usability and white space. Usability, whether real or perceived, has a psychological value on the experience of using a website, and therefore websites with good usability add value to online experiences by providing an effortless positive online experience (Okwonkwo, 2005). Usability provides economic utility (or value) to the users by enhancing the quality of their experience, and the application of good usability principles to website design in e-commerce provides discernible economic outcomes. Casaló, Flavián, and Guinalíu (2008) found that good website usability increased customer satisfaction and loyalty and was significantly correlated with an 
increase in positive word-of-mouth for financial service websites. In a similar study, Bolchini, Garzotto, and Sorce (2009) demonstrated that good website usability was correlated with a positive perception of brand image, which is important for maintaining customer relationships. In addition, Nielsen and Gilutz (2003) analyzed 42 cases of website redesigns and found that there was an average improvement of $100 \%$ in sales and conversions after redesigns were made by applying usability principles, including the effective use of white space. The return on investment for good usability has been demonstrated, but few researchers have isolated the effects of white space on websites independently of the application of other good usability principles. Clearly, the use of white space plays a role in usability, and usability has an economic value. However, to our knowledge, no studies have focused on the direct impact of manipulating either the total amount of white space present or the amount of white space between content on usability.

White space, trust, and credibility online. In a study on the "design look" of web sites, Fogg et al. (2003) showed that the most prominent issue in consumers' evaluations of a website's credibility lay in the design of the site. They further stated that almost $50 \%$ of consumers' comments about credibility was related to the design in general or was focused on specific elements such as the layout (with proper use of white space as a structural differentiator) and colors. A study by Wang and Emurian (2005) showed similar results: consumers judged web sites' trustworthiness based not just on the graphical elements themselves, but also based on good layouts structures that made the websites look "comfortable to read, navigate, and use." These studies highlight the 
importance of white space in the context of website layouts that cater to the consumer looking to purchase online. Promoting trust and credibility is extremely important to the e-commerce retailer in influencing consumers' purchasing decisions. However, although white space is mentioned in relation to the concept of "good layout," extrapolating or isolating the effects of the use or amount of white space on influencing consumer perceptions of credibility has not been attempted.

\section{The Online Retail Environment and Purchasing Behavior}

The rapid growth of e-commerce in the 1990s was met with widespread adoption and acceptance by consumers and retailers alike (Kalakota \& Whiston, 1997). Indeed, the rapid growth in e-commerce sales through the 2000s has remained strong as reflected by the total yearly sales through e-commerce channels that grew from $\$ 27.6$ billion in 2000 to $\$ 143.4$ billion in 2009 (White \& Ariguzo, 2011). In the latest U.S. Census Bureau report from the Retail Indicators Branch, \$224.4 billion in total sales were made via e-commerce in 2012 alone.

The interaction of consumers with e-commerce has thus fundamentally changed purchasing behavior (Bellman et al., 1999) by eliminating the constraints of time and space that limit the traditional retail experience of the physical world (Kalakota \& Whiston, 1997). Websites have also become a valuable point-of-contact for retailers and act not just as a marketplace to sell products or services, but also function as a communication channel with current and potential customers (Hoque \& Lohse 1999).

It is well-known that the physical environment in traditional retail contexts shapes customer behavior (Bitner, 1992; Donovan \& Rossiter, 1982). Baker (1986) proposed a 
conceptual model with three categorical factors of a retail environment that influence purchasing behavior: (a) social factors (e.g., the people present); (b) ambient factors (e.g., smells, sounds, and other cues that may or may not be consciously perceptible); and (c) design factors (e.g., store layout). The design factors of retail stores such as the layout, color, and clutter present influence emotional states, which therefore affect purchasing behavior (Baker, 1986). Critically, the layout and the physical arrangement of items and furniture serve a functional purpose that can facilitate consumer goals (Bitner, 1992). For online retail contexts, Eroglu, Machleit, and Davis (2001) have introduced a model that also factors environmental cues as part of the shopping experience. Their model provides a framework based on the Stimulus-Organism-Response (S-O-R) paradigm originally developed by Mehrabian and Russell (1974), in which online environmental cues (stimuli) influence the internal state of the individual (organism) leading to purchasing outcomes (response). As the online shopping experience differs significantly from the context of traditional retail and relies primarily on visual cues via screens, in Eroglu et al.'s (2001) model they proposed that the environmental cues can therefore be broken down by task relevance. High task-relevance refers to content that directly enables users to complete purchasing goals, for example, pictures of products and verbal descriptions or reviews. Low task-relevance refers to cues of the online environment (such as amount of white space, colors used, and fonts) that are supplementary to the experience that do not affect task-completion directly but play a part in eliciting moods and maintaining a certain brand image. These cues affect the 
individual's internal states on cognitive and affective levels which, in turn, elicit approach or avoidance response outcomes on the online shopping experience.

In an empirical study of the S-O-R model on online retail, Mummalaneni (2005) found that design factors had a statistically significant effect on consumer ratings of pleasure and likelihood of future purchases, and yet also found that time and dollar amount spent by participants were not significantly influenced by design factors. Mummalaneni offered an explanation for the lack of purchasing behavior as influenced by the characteristics of the student participants who may have had budgetary constraints typically associated with student lifestyles. In his conclusion, Mummalaneni proposed that website design is critical to the success of e-commerce websites, and recommended that future research focus on testing the S-O-R framework by examining the design variables that affect virtual store environments and purchase behaviors.

In a related study of three online bookstores, Liang and Hai (2002) found that participants most frequently cited the design as the reason for their attraction to one online store over other stores. Design was followed by price, reputation, and special product needs. Design quality of the website (as assessed by both consumers and experts) was significantly correlated with consumers' self-reported likelihood to return for future purchases and was also consistent with the actual purchase outcomes during the study. Thus, design quality was not only a predictor of consumers' choice to visit, but more importantly, of merchandise sold, demonstrating a measureable economic outcome of applying good design principles to online retail websites. 
Although existing literature has proposed that environmental design cues influence consumers on shopping sites, few studies have attempted to quantify the specific effects of variables that contribute to overall satisfaction (McKinney, 2004). Again, white space, although a ubiquitous design factor present in all online retail contexts, has not yet been quantifiably measured in isolation of other design factors as an independent variable on shopping behavior.

\section{White Space and Consumer Perceptions}

White space, although described as an absence of content, is not devoid of meaning and influence. Indeed, there has been is a long history of designers speculating on the value and function of white space in art, design, copy, and advertising (Book \& Schick, 1997; Drewniany \& Jewler, 2011). In graphic design, skillful employment of white space, color balance and contrast were key principles in producing and evaluating good trademark designs, which in turn are significant factors for conveying an idea or selling products (Chen, Cai, Huang, \& Ku, 2003; Levine, 2000). Similarly, in commercial visual advertising, Pracejus, Olsen and O'Guinn (2006) reported that white space is believed to convey "elegance, power, leadership, honesty, trustworthiness, a modem nature, and a refined taste associated with the upper social strata" by a survey of creative directors at major advertising agencies in North America. In their empirical study involving naïve consumers, Pracejus et al. also found that consumer perceptions of quality, prestige, and purchase intentions were significantly influenced by the use of white space, which mirrors the beliefs held by social-cultural art history theories and the creative directors. 
These theories in art and advertising demonstrate a relationship between white space and the perception of luxury or quality consistent with a study by Mortelmans (2005) of retail clothing stores. He observed a relationship between the design of displays in shopping windows and the prestige of the store brand. Windows that maximize emptiness were closely correlated with the most prestigious stores (such as Yves Saint Laurent and Salvatore Ferragamo), whereas store displays that conveyed an impression of bulk sales and chain stores with low prices were correlated with less prestigious stores (such as $\mathrm{H} \& \mathrm{M}$ and Bennetton).

Subjective price perception. Lichtenstein and Burton (1989) found some evidence that consumers' subjective perception of product quality was correlated to objective measures of quality based on empirical testing, independent and expert opinions and user surveys. Objective measures of quality, in turn, have been found to be correlated to price across multiple product categories (e.g, Gerstner, 1985; Morris \& Bronson, 1969; Oxenfeldt, 1950). These findings provide support for the price-quality schema; the general belief held by consumers that levels of price are positively correlated to levels of quality (as defined by Lichtenstein, Ridgway, \& Netemeyer, 1993), and viceversa.

In addition to the price-quality schema, price perception is also known to be moderated by general awareness of prices (Dickson \& Sawyer, 1990), socio-economic standing (Gabor \& Granger, 1961) as well as demographic factors such as age, gender and experience (Munnukka, 2008). Perceived value could also depend on a variety of 
other internal factors such as personality, preferences and current affective states that can exist independently or interact with the environmental cues during a shopping experience.

Prestige and luxury. Mortelmans (2005) attributed the relationship between emptiness and luxury to Norbert Elias' (1982) civilization theory that proposes that higher socio-economic classes acquired the ability to control impulses through the process of civilization. They are therefore better able to control the natural human urge to fill empty spaces, a phenomenon popularly known by the Latin expression, "horror vacui" (fear of emptiness). The power to retrain the self from this urge is thus classified as a sign of distinction and therefore, "amor vacuii" (love of emptiness) becomes a marker for class, prestige, and luxury.

In formal microeconomic theory, scarcity restricts supply, and therefore forces the price of scarce commodities to rise to the level of where decreasing demand (due to rising prices that places the product out-of-reach for an increasing number of consumers) meets the available supply. The preferences of consumers are assumed to be independent of the supply. That is, scarcity should have no psychological effect on value although it increases the market value (price) and decreases the demand due to the reduced buying power of consumers as prices increase (Lynn, 1991). However, there have been historical assumptions that scarcity increases the perceived value of products (Cialdini, 1993). There is evidence to suggest that, contrary to economic theory that scarcity does not have a psychological effect, people come to associate scarcity with expensiveness and to associate expensiveness to quality, thereby increasing the desirability of expensive 
products (Monroe, 1973). This shows a link between perceived scarcity and assumptions of price and quality, which are hallmarks of luxury.

Perhaps the controlled window displays and extensive use of white space by luxury brands in Mortelmans' observations in 2005 are an extension of efforts by a luxury market that seeks to perpetuate an illusion of scarcity (Catry, 2003). This study proposes that white space could act as a visual indicator of scarcity and therefore indirectly increase the perception of price and value of luxury products, generalizable to online retail contexts.

\section{Purpose and Research Questions}

Many questions remain on the quantifiable benefits of white space as an isolated design variable on web interfaces. The purpose of this study was to examine the effects of white space a design factor with a quantifiable measure and to examine the relationship between varying amounts of white space and perception of monetary value of products displayed on e-commerce websites. The main research question posed by this project is: How does white space affect consumer perceptions of monetary value of items sold via e-commerce channels? In addition, this study sought to answer the question: While controlling for information density and the total amount of white space, how does the amount white space between objects affect consumer perceptions of monetary value? 


\section{Method}

\section{Participants}

A total of 108 participants were recruited for this study. All participants of this study were students enrolled in General Psychology classes and recruited through the Department of Psychology of San José State University through an online subject pool management system, SONA. A power analysis using G*Power (Faul, Erdfelder, Lang, \& Buchner, 2007) showed that the largest sample size for any analysis needed to detect a medium effect size $(\alpha=.05$, power $=.80)$ was 108 . All participants had to meet the following criteria in order to participate:

1) Have no known motor or sensory problems besides minor vision impairments corrected by regular prescription glasses or contact lenses.

2) Be an experienced computer user who spent an average of at least two hours using a computer each week.

Participants who met the criteria and completed the study were compensated with course credit for their time. A raffle to win a $\$ 50$ gift card was conducted at the conclusion of the study. Participants' ages ranged between 19 and 33 years $\left(M_{\text {age }}=19.89\right.$ years, $S D=1.75$ years $)$. Overall, $93.5 \%$ of participants had previous experience shopping online, and $8.3 \%$ had previous experience of buying furniture online. Cumulatively, the participants self-reported approximately $69.3 \%$ of the time that they spent between $\$ 1$ to $\$ 100$ shopping online per month. All participants gave their informed consent. This study was approved by the San José State University Institutional Review Board (See Appendix G). 


\section{Instruments and Materials}

Participants used Dell Optiplex 990 desktop computers running a Windows 7 Professional (64 bit) operating system with an Intel Core i7-2600K CPU (3.40 GHz) processor and 4GB of RAM. The displays were 20" widescreen liquid crystal display (LCD) monitors with 1600 x 900 resolution running at 60Hz. Standard keyboards and mice were used as input devices. A web browser, Mozilla Firefox 20, was also used.

For the purposes of this study, a generic retail furniture website was created by the experimenter with chairs displayed as items for sale as visual stimuli. The website layout visually mimics current retail furniture e-commerce websites, complete with visual details such as headers and navigation, which were non-interactive for the purposes of this experiment (See Figure 1). The stimuli (chairs) and context (furniture retail website) were chosen for the following reasons:

1) Participants were assumed to have minimal experience buying furniture (either online or in general) as young adults, thereby minimalizing the likelihood that participants had knowledge of prices they could draw upon.

2) The estimated value and/or quality of the chairs had to be made purely on the visual characteristics of the chair and environmental cues alone.

3) Chairs and furniture were assumed to be gender neutral products.

4) Chairs and furniture would elicit minimal affective reactions.

5) It is reasonable to assume that one chair could come in different colors, and each color would be of the same price. 


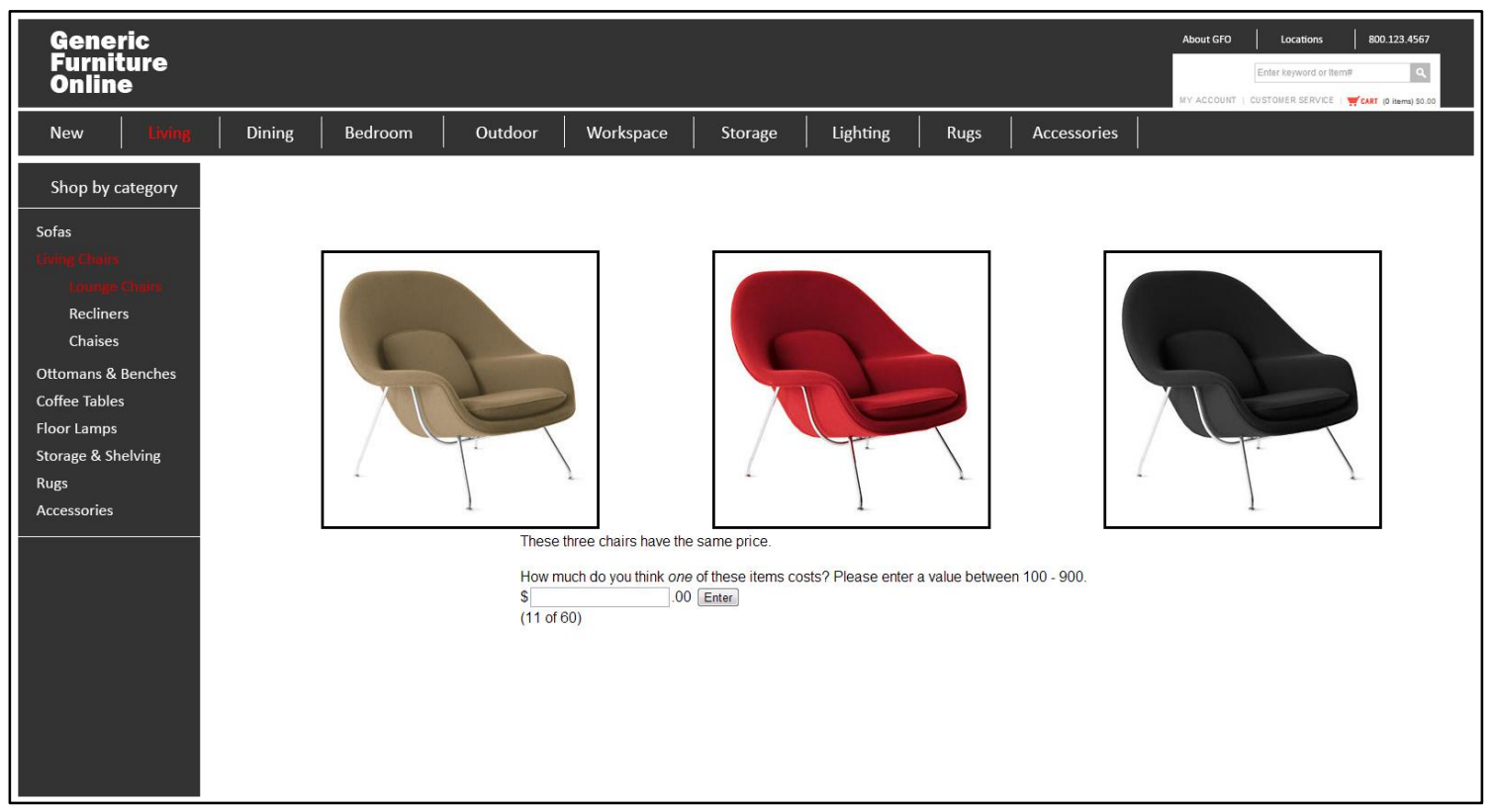

Figure 1. Retail furniture website created by experimenter.

In the two-image condition (large total white space), two chairs were displayed on the website, while in the three-image condition (small total white space), three chairs were displayed. Chair images were curated from a convenient sample of websites of well-known retailers that sell chairs: Design Within Reach (http://www.dwr.com/), Ikea (http://www.ikea.com/), Target (http://www.target.com/), Overstock.com (http://www.overstock.com), and Home Depot (http://www.homedepot.com/). Only photos of chairs taken from an isometric perspective on a white background were used. Additionally, only chairs that were of a uniform color (no patterns) were chosen. Digital editing to recolor and resize the visual stimuli to standardize the sizes, colors, and contrasts was done using Adobe Photoshop CS 6 Extended. Occasionally, images were 
digitally manipulated to create extra images to satisfy the exact number of images (per set of three) needed for the entire experiment.

Images used as stimuli were manipulated to exact dimensions of $300 \times 300$ pixels $\left(90,000 \mathrm{px}^{2}\right)$. A total of 20 image sets of 3 were created, with each set featuring the same chair in different colors (See Appendix B). A custom-made program was developed for displaying stimuli and recording participant inputs using the Python programming language and the Django web framework. The sets of stimulus images and participant data were stored in an SQLite3 database. The entire application was served by a Mac OS $\mathrm{X}$ computer through web servers (Django and Twistd). Thus, participants were able to use a web browser to interact with the stimuli to add to the realism of the experiment as an online shopping experience.

\section{Design and Procedure}

After giving informed consent, all participants were asked to be seated comfortably in front of the monitor with their face parallel with the screen approximately 20 inches away. Instructions were given to participants to "guess the amount of one of the items" on the website that they saw and to key in the approximate monetary value of items on the screen in a text box. Below the images displayed, there was also a line of simple text with the instruction: "How much do you think one of these items costs?

Please insert a dollar value between 100 and 900." The input text box sat below this line of instruction (See Figure 2). If participants entered a value outside of the specified range, an error message in red appeared with the additional instruction, "You must enter a value between $\$ 100$ and 900 !" for that trial (see Figure 3). 
This study used an experimental mixed factorial $(2 \times 3)$ design. The first, between-subject, factor manipulated the total amount of white space by increasing or decreasing the number of images displayed (two images or three images). The second, within-subject, factor manipulated the white space between images viewed (near, medium, and far), while holding the amount of white space constant. Participants were randomly assigned to one of two experimental groups via a random number generator. One group was exposed to a two-image condition with a large amount of total white space $\left(754,875 \mathrm{px}^{2}\right.$ of total white space), while the other group was exposed to a threeimage condition with a smaller amount of total white space $\left(664,875 \mathrm{px}^{2}\right.$ of total white space). Total white space is calculated by taking the area of the white space, not including the area of navigation and area of images (See Figure 3).

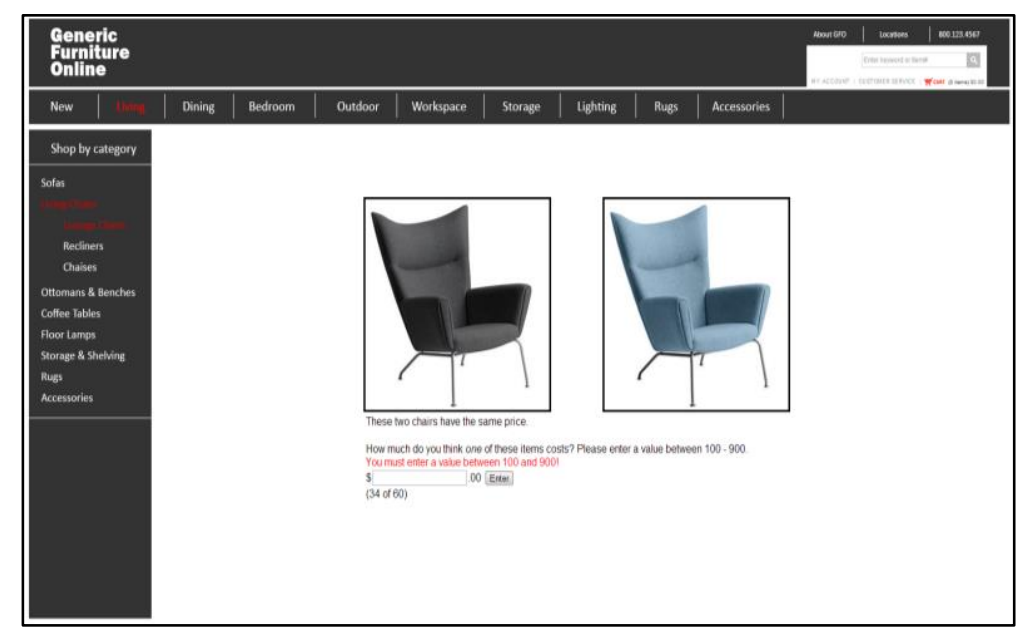

Figure 2. Instructions and error message displayed if participant attempted an input outside the specified value range. 


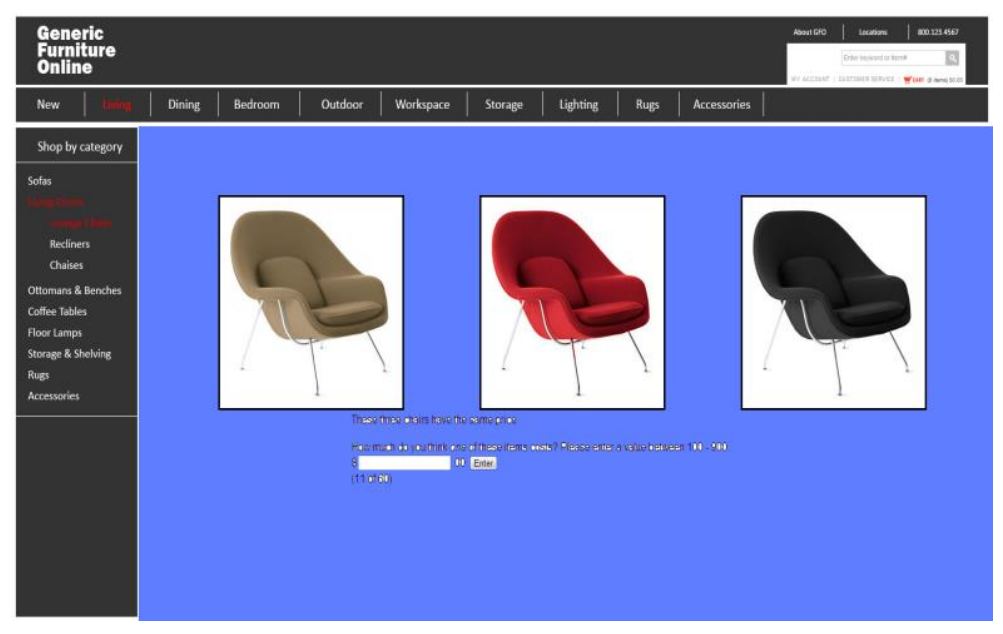

Figure 3. Area of total white space is colored blue in this sample displaying 3 images. Total white space in this sample is $664,875 \mathrm{px}^{2}$.

The linear order of images presented was randomized for each trial. For participants in the two-image group, the program randomly selected two images out of a three-image set and randomized the order displayed. The 20 image sets created were displayed with a small $\left(12,000 \mathrm{px}^{2}\right)$, medium $\left(24,000 \mathrm{px}^{2}\right)$ and large $\left(36,000 \mathrm{px}^{2}\right)$ amount of white space between objects, thereby making the horizontal distance between objects near (40 px), medium (80 px) and far (120 px), respectively. These distances were chosen so that the largest distance would still accommodate the visual arrangement of at least three objects in a horizontal plane on a 1600 x 900 screen (See Appendix C). Trials were determined by uniform random sampling without repetition, using the Python function "random.sample()" to generate trials displayed on the screen for each participant. That is, all participants saw all 20 image sets at all levels of between-object white space, with trials and images within each set presented in a random order (see 
Appendix B). A total of 60 randomized trials were recorded for each participant. Each participant provided three data sets for the between-object white space: small (20 trials), medium (20 trials), and large (20 trials). At the conclusion of the experiment, a short demographic questionnaire was administered via the web browser (See Appendix D).

\section{Measures}

In each trial, participants entered a dollar value estimate of the cost of one of the items displayed, within the range of 100 to 900 (dollars). Participants used the keyboard and "Enter" button to confirm their input. If an input fell outside the range of 100 to 900 , an error message appeared and the participant would repeat the trial. Mean values were then computed for each data set.

Individual Internet usage and online shopping experience data were collected from participants with a web-form questionnaire. Participants self-reported by selecting a response from a range of mutually exclusive options on an ordinal scale on their weekly hours spent using the internet, frequency of online shopping and monthly shopping expenditures online.

\section{Results}

For all analyses, $\alpha$ was set to .05 . In the condition featuring two-images and a large amount of white space $\left(754,875 \mathrm{px}^{2}\right)$, there were 55 participants, and in the threeimage condition with a smaller amount of white space $\left(664,875 \mathrm{px}^{2}\right)$ there were 53 participants. Participants in each condition were exposed to three levels of white space distances between images ( $40 \mathrm{px}, 80 \mathrm{px}$, and $120 \mathrm{px}$ ) and the estimated dollar value of the 
item shown was recorded. Table 1 depicts the descriptive statistics obtained for these conditions.

Table 1

Descriptive Statistics for the Estimated Value (USD) by Total White Space and White Space Between Images

\begin{tabular}{lrrr}
\hline \multicolumn{2}{l}{ Total White Space \& White Space Distance Between } & $M$ & $S D$ \\
\hline $\begin{array}{l}\text { Large White Space }(N=55) \\
\text { (2-images, 754,875 } \mathrm{px}^{2} \text { of White Space) }\end{array}$ & & & \\
& $40 \mathrm{px}$ & 313.01 & 118.96 \\
& $80 \mathrm{px}$ & 313.45 & 122.37 \\
& $120 \mathrm{px}$ & 317.69 & 120.59 \\
& Total & 315.05 & 119.71
\end{tabular}

Small White Space $(N=53)$

(3-images, 664, $875 \mathrm{px}^{2}$ of White Space)

$\begin{array}{rrr}40 \mathrm{px} & 325.60 & 116.99 \\ 80 \mathrm{px} & 328.52 & 120.34 \\ 120 \mathrm{px} & 333.40 & 118.59 \\ \text { Total } & 329.17 & 117.74\end{array}$

Total for Each Level of White Space Between

\begin{tabular}{rrr}
$40 \mathrm{px}$ & 326.32 & 116.45 \\
$80 \mathrm{px}$ & 328.95 & 120.14 \\
$120 \mathrm{px}$ & 332.09 & 117.62 \\
Total & 322.11 & 118.73 \\
\hline
\end{tabular}

After an exploratory data analysis, there appeared to be gender differences in our results. Therefore, to test for possible gender differences in perceived value, self-reported gender (male vs. female) was as an additional factor in our analyses. A three-factor mixed ANOVA was performed on the data collected and the results are presented in 
Table 2. There was a significant main effect of gender and the amount of white space distance between images. Simple comparisons using the Fisher-Hayter post-hoc test were calculated to analyze the differences between all distances of white space between stimuli images presented, and effect size was measured using Cohen's $d$, as seen in Table 3. A comparison of the largest white space difference (40px vs. 120px) between images shown was significant at $p<.05$. None of the other effects were statistically significant.

Table 2

Three-way ANOVA Results

\begin{tabular}{rrrrr}
\hline Effect & $F$ & $d f$ & $p$ & $\eta_{\mathrm{p}}{ }^{2}$ \\
\hline Distance Between & 3.319 & 2,208 & .038 & .031 \\
Total White Space & .382 & 1,104 & .538 & .004 \\
Gender & 6.248 & 1,104 & .014 & .057 \\
Distance Between * Total White Space & .201 & 2,208 & .820 & .002 \\
Distance Between * Gender & .691 & 2,208 & .503 & .007 \\
Total White Space * Gender & .384 & 1,104 & .537 & .004 \\
Distance Between * Gender * Total White Space & 2.789 & 2,208 & .066 & .026 \\
\hline
\end{tabular}

Table 3

Simple Comparisons for White Space Distance Between

\begin{tabular}{rrrrr}
\hline Treatment Comparison & $q_{F H}$ & $d f$ & $p$ & $d$ \\
\hline 40 px vs 80 px & 1.29 & 2,103 & .761 & 0.08 \\
80 px vs 120 px & 2.41 & 2,103 & .270 & 0.16 \\
40 px vs 120 px & 6.24 & 2,103 & .038 & 0.24 \\
\hline
\end{tabular}




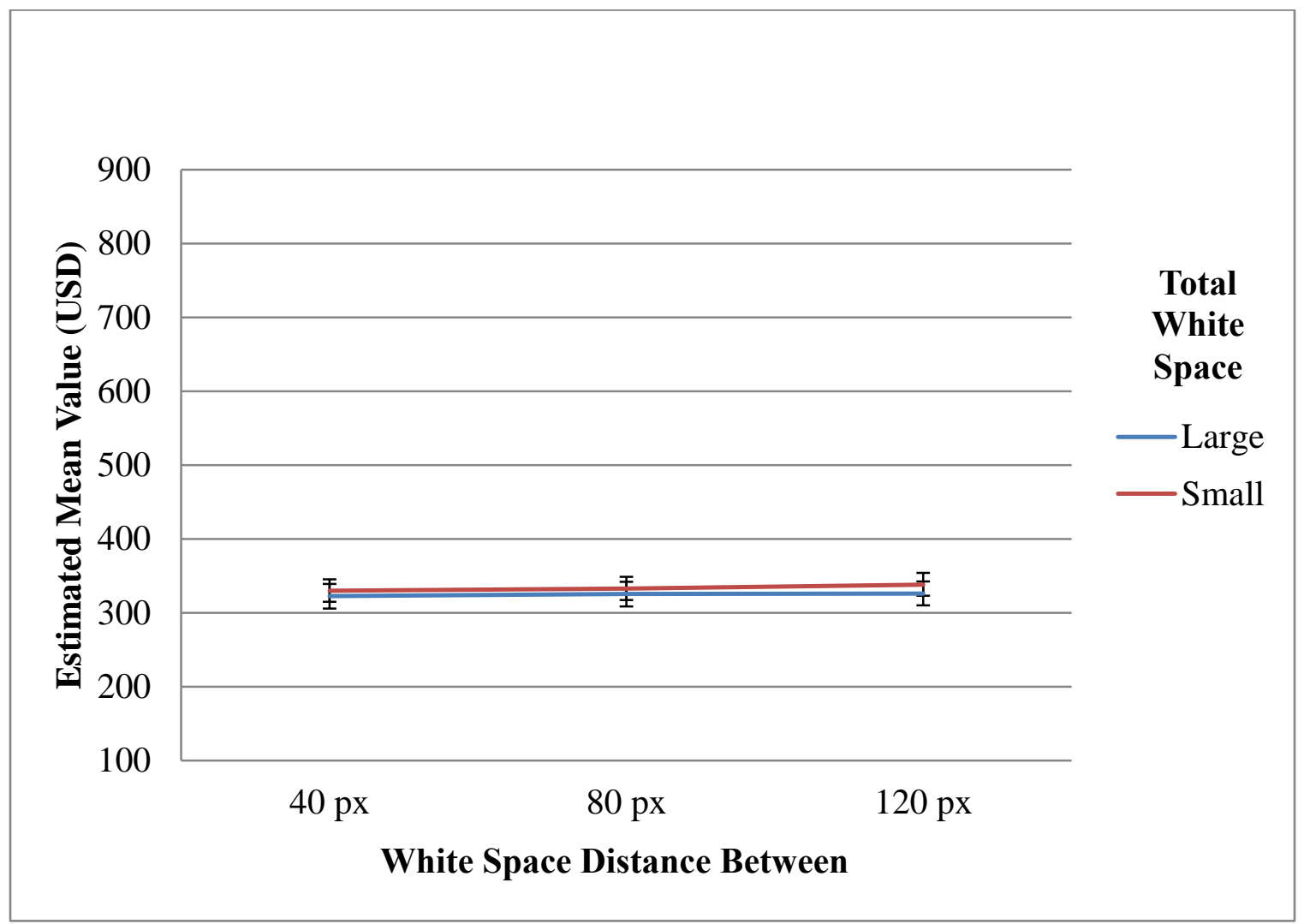

Figure 4. Graph of estimated mean values (USD) by white space distances between images separated by total white space. 


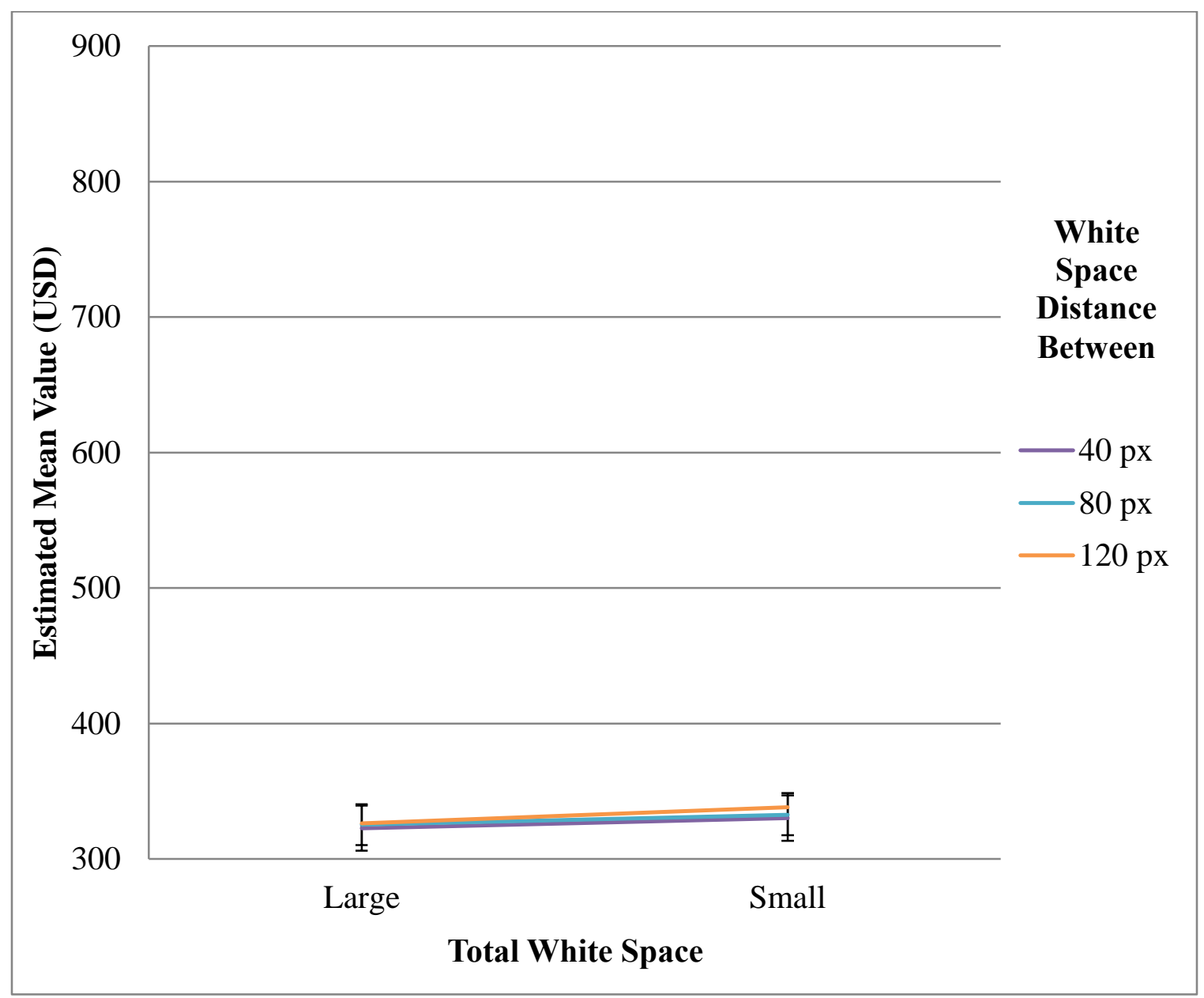

Figure 5. Graph of estimated mean values (USD) by total white space separated by distances between images. Note that the Y-axis has been truncated to start at 300 (instead of 100).

\section{Gender}

There was a significant main effect of gender on the overall value estimates made by participants, 67 females, and 41 males. Descriptive statistics by total white space, gender, and white space distance between are depicted on Table 4. On average, across all 
trials of both conditions, female participants estimated a higher value $(M=350.67, S D=$ 115.29) than male participants $(M=293.55, S D=115.21)$, with a significant mean difference of $\$ 57.12, F(1,104)=6.25, p=.014$.

Table 4

Descriptive Statistics for the Estimated Value (USD) by Total White Space, Gender, and White Space Between Images

\begin{tabular}{|c|c|c|c|}
\hline $\begin{array}{r}\text { Total White Space, Gender and White Space } \\
\text { Distance Between }\end{array}$ & $N$ & $M$ & $S D$ \\
\hline \multirow{2}{*}{\multicolumn{4}{|c|}{$\begin{array}{l}\text { Large White Space } \\
\text { (2-images, } 754,875 x^{2} \text { of White Space) }\end{array}$}} \\
\hline & & & Male \\
\hline $40 \mathrm{px}$ & 20 & 277.68 & 114.43 \\
\hline $80 \mathrm{px}$ & 20 & 274.33 & 117.71 \\
\hline $120 \mathrm{px}$ & 20 & 286.25 & 116.02 \\
\hline Male Total & 20 & 279.42 & 115.18 \\
\hline \multicolumn{4}{|l|}{ Female } \\
\hline $40 \mathrm{px}$ & 35 & 348.35 & 114.43 \\
\hline $80 \mathrm{px}$ & 35 & 354.49 & 117.71 \\
\hline $120 \mathrm{px}$ & 35 & 349.14 & 116.02 \\
\hline Female Total & 35 & 350.69 & 115.17 \\
\hline
\end{tabular}

Small White Space (3-images, 664, $875 p^{2}$ of White Space)

Male

$\begin{array}{rlll}40 \mathrm{px} & 21 & 303.80 & 114.43 \\ 80 \mathrm{px} & 21 & 308.64 & 117.71 \\ 120 \mathrm{px} & 21 & 310.63 & 116.02 \\ \text { Total } & 21 & 307.69 & 115.17\end{array}$

Female

$40 \mathrm{px} \quad 32 \quad 347.40$

114.43 


$\begin{array}{rlll}80 \text { px } & 32 & 348.39 & 117.71 \\ 120 \text { px } & 32 & 356.17 & 116.02 \\ \text { Female Total } & 32 & 329.17 & 117.74\end{array}$

Total for Both Conditions

\begin{tabular}{rrrr}
\multicolumn{1}{l}{ Male } & & & \\
$40 \mathrm{px}$ & 41 & 290.74 & 146.32 \\
$80 \mathrm{px}$ & 41 & 291.48 & 150.51 \\
$120 \mathrm{px}$ & 41 & 298.44 & 148.36 \\
Male Total & 41 & 293.55 & 115.21 \\
Female & & & \\
$40 \mathrm{px}$ & 67 & 347.88 & 89.60 \\
$80 \mathrm{px}$ & 67 & 351.48 & 92.17 \\
$120 \mathrm{px}$ & 67 & 352.65 & 90.85 \\
Female Total & 67 & 350.67 & 115.29 \\
\hline
\end{tabular}

Further post-hoc analyses were conducted on the effect of white-space distance between images as a within-subjects factor. White space distance between images had a significant effect on value estimations for male participants, $F(2,78)=3.87, p=.025$, but it did not have a significant effect for female participants, $F(2,130)=1.10, p=.37$. Simple comparisons using Fisher-Hayter post-hoc tests were made for pairs of white space distances for each gender. As seen in Table 5, male participants reported significantly different values for the $40 \mathrm{px}$ and 120 px pair, with a mean difference of $\$ 7.70$. Figure 6 shows side-by-side graphs of estimated value by each gender, showing the estimated values by total white space at the three different white space distances. 
Table 5

Simple Comparisons of White Space Distance Between by Gender

\begin{tabular}{ccccc}
\hline Treatment Comparison & $q_{F H}$ & $d f$ & $p$ & $d$ \\
\hline Females & & & & \\
40 px vs 80 px & 1.52 & 2,130 & .619 & .13 \\
80 px vs 120 px & 0.50 & 2,130 & .978 & .04 \\
40 px vs 120 px & 2.01 & 2,130 & .454 & .76 \\
& & & & \\
Males & & & & .03 \\
40 px vs 80 px & 0.34 & 2,78 & .995 & .33 \\
80 px vs 120 px & 3.23 & 2,78 & .119 & .49 \\
40 px vs 120 px & 3.57 & 2,78 & .010 & \\
\hline
\end{tabular}
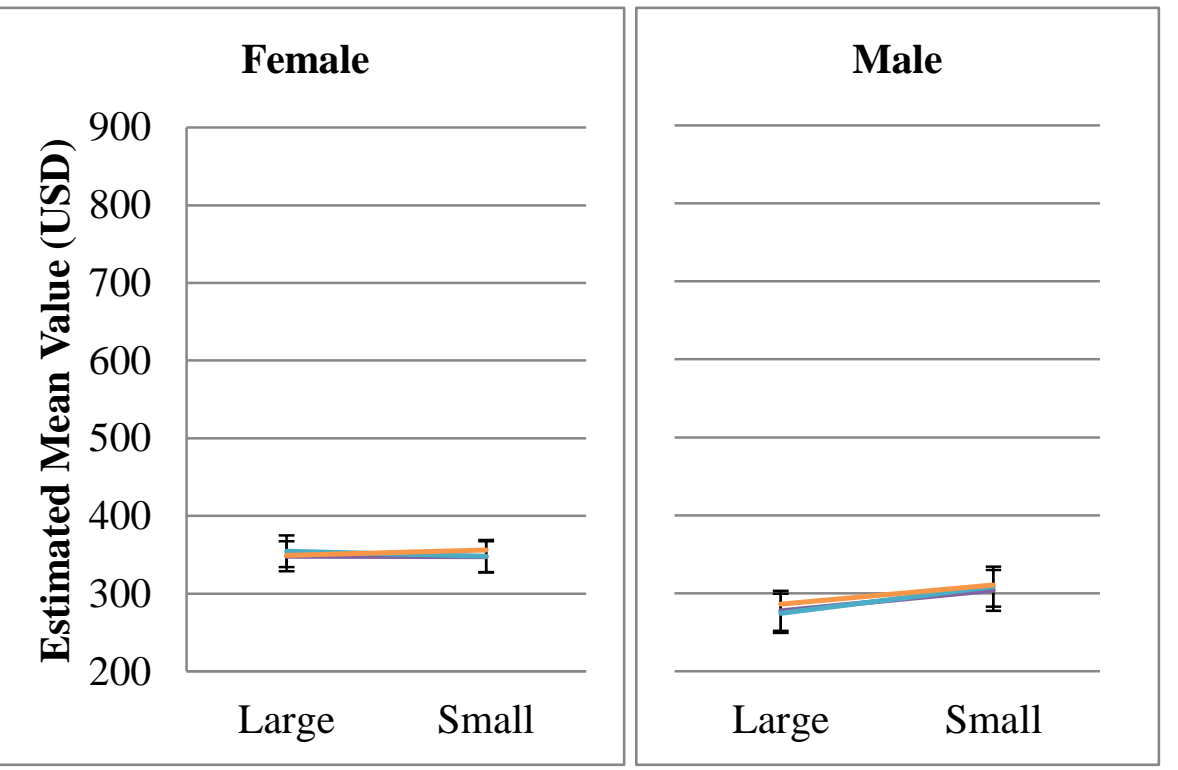
White Space Distance Between
$-40 \mathrm{px}$ $80 \mathrm{px}$ $120 \mathrm{px}$

\section{Total White Space}

Figure 6. Estimated mean values by female and male participants by total white space and white space distance between. Male participants, on average, estimated mean values at a lower range than female participants. Note that the $\mathrm{Y}$-axis has been truncated to start at 200 (instead of 100). 
Self-reported online shopping frequency by males and females are displayed in Figure 7. Because of small cell sizes across categories, the two lowest categories (Never and Very Rarely) were combined into one category, and the rest were combined into another category (Once a Month or More). We compared the genders on their frequency of online shopping using these two new categories. Table 6 depicts the frequency and percentage of female and male participants for the two categories of shopping behavior. A chi-square test of independence revealed that the relationship between gender and online shopping behavior was not significant, $\chi 2(1)=3.19, \mathrm{p}=.07, \phi=.17$.

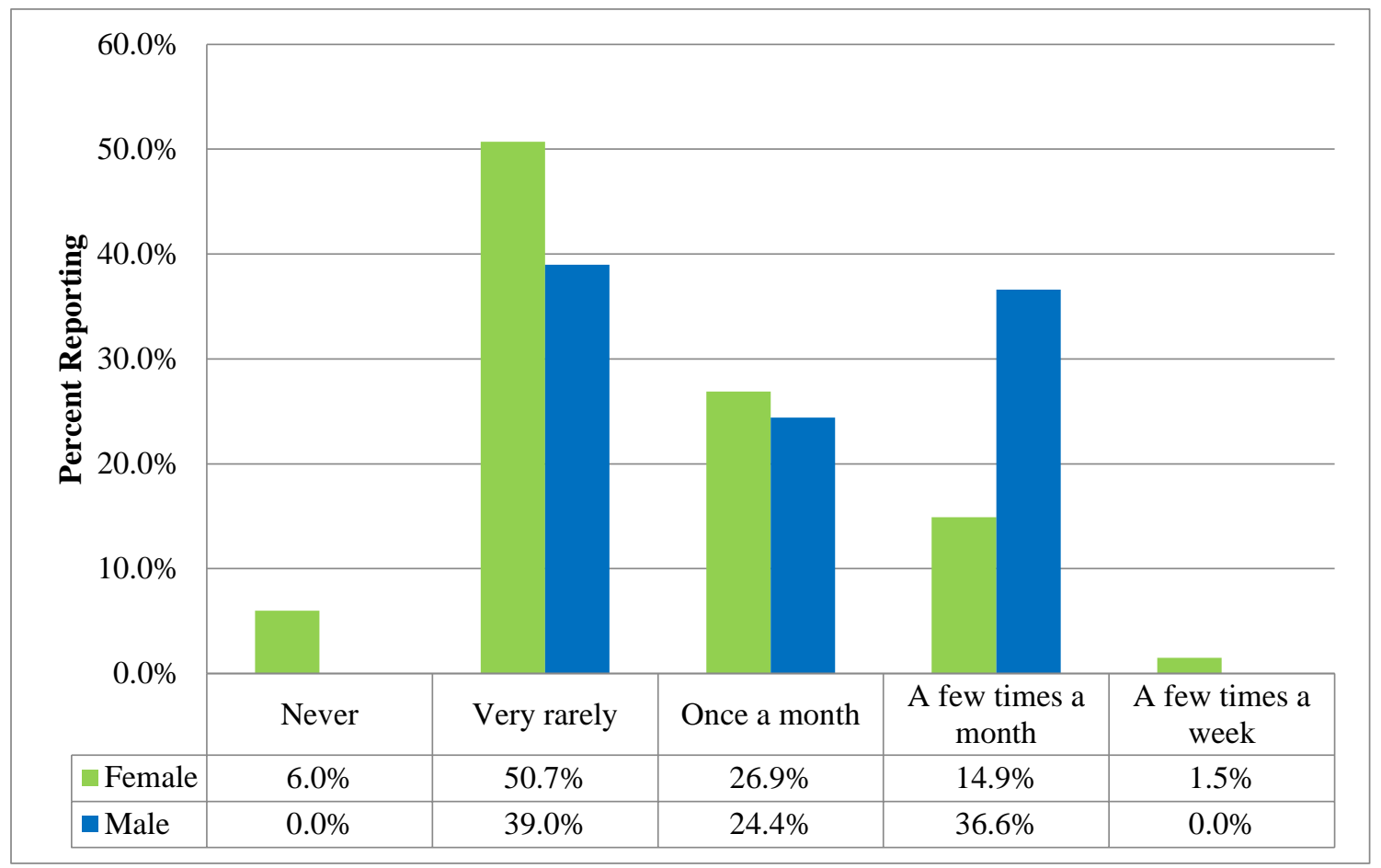

Figure 7. Frequency of online shopping in percent, as reported by male and female participants. 
Table 6

Frequency of Online Shopping for Each Gender

\begin{tabular}{ll}
\hline Category & $n(\%)$ \\
\hline Females & \\
Never/Very Rarely & $38(35.2 \%)$ \\
Once a Month or More & $29(26.9 \%)$ \\
Males $\quad$ Never/Very Rarely & $16(14.8 \%)$ \\
Once a Month or More & $25(23.1 \%)$ \\
\hline
\end{tabular}

Self-reported online shopping amount (in USD) per month by males and females are displayed in Figure 8. Because of small cell sizes across categories, categories below $\$ 100$ were combined into one category, and categories above $\$ 100$ were combined into another category. We compared the genders on their amount spent in online shopping using these two new categories. Table 7 depicts the frequency and percentage of female and male participants for the two categories of shopping behavior. A chi-square test of independence revealed that the relationship between gender and amount spent per month in shopping behavior was significant, $\chi^{2}(1)=6.21, p=.013, \phi=.24$. 


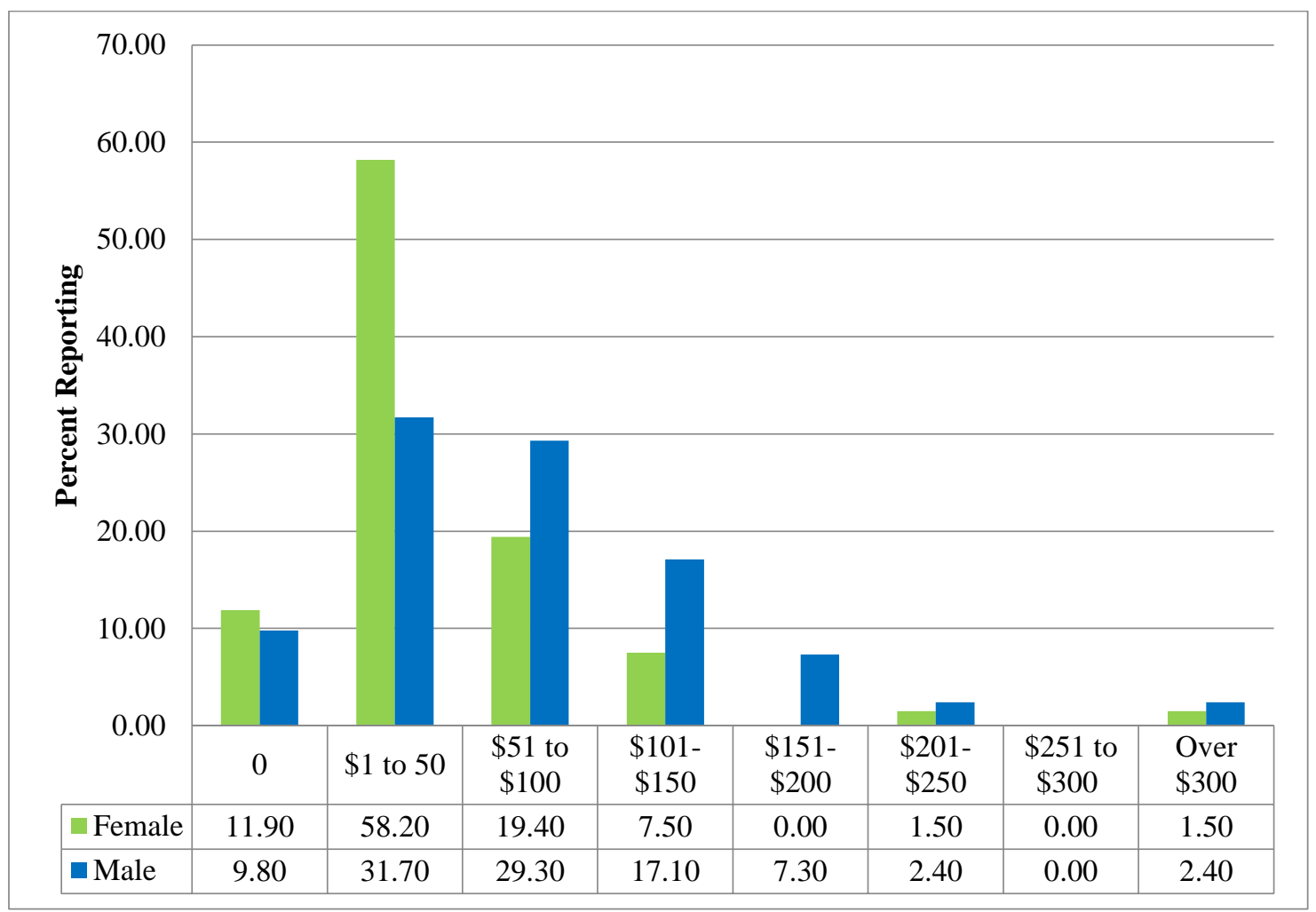

Figure 8. Online spending per month in percent, as reported by male and female participants.

Table 7

Amount Spent Per Month in Online Shopping for Each Gender

\begin{tabular}{crc}
\hline \multicolumn{2}{c}{ Category } & $n(\%)$ \\
\hline Female & $\$ 100$ or less & \\
& More than $\$ 100$ & $60(55.6 \%)$ \\
Males & & $7(6.5 \%)$ \\
& $\$ 100$ or less & $29(26.9 \%)$ \\
& More than $\$ 100$ & $12(11.1 \%)$ \\
\hline
\end{tabular}




\section{Discussion}

Environmental cues are an important determinant of online shopping behavior (Eroglu, Machleit \& Davis, 2001), though little is known about the direct effects of lowtask relevant environmental cues, such as white space, on the perception of items sold via e-commerce channels. This study investigated two primary factors of white space on participants' perception of the dollar-value of items sold on web sites: the total amount of available white space, and the white-space distance between images. In addition, gender differences were examined.

\section{Total white space}

In the context of a visual scene (such as the finite constraints of a computer screen), there is an inverse relationship between white space and content. Therefore, the total amount of white space cannot be manipulated independently without manipulating the amount of content. This study compared two levels of total white space by using conditions with a website containing two images (large total white space) and three images (small total white space) arranged on a horizontal plane and found no significant different between the values estimated by participants on the dollar-value of the object(s) shown. This result suggests that the amount of white space on website may not influence the subjective perception of items' dollar value on websites at the effect size we predicted. In other words, for our predicted effect size, the amount of content displayed appears not to have triggered psychological effects on participants' perceptions of prestige, luxury, or scarcity, which would have influenced their estimates of the cost of the items shown. One possible explanation for this result is that the total white space 
difference between a website with two images and three images was too small of a difference to produce a detectable and statistically significant effect on the value estimations by participants in this study. Our observations did not show a statistically significant difference between the two conditions for either male or female participants, although there appears to be an upward trend in value estimations by male participants as the number of images increased, and total white space decreased (see Figure 6). No such trend is apparent in the data for female participants.

\section{White space distance between images}

By varying the distances between displayed items on the constrained visual area of a computer screen, this study directly manipulated the layout while holding the total amount of white space constant. Three different distances were used between displayed images: 40 px, 80 px, and 120 px. Critically, a greater amount of white space distance between images had a positive effect on participants' estimations of dollar-value of the items. This finding demonstrates that increasing the amount of white space that immediately surrounds displayed items has a positive effect on the perceived dollar-value of the items, at least in this context. The relationship between objects displayed appears to affect the subjective perception of dollar-value estimations by the participants in this study. It is possible that greater amounts of white space between objects (rather than the total available white space) promoted a perception of less "clutter," a design factor that is known to increase subjective satisfaction of web sites (Rau, Gao \& Liu, 2007).

Ultimately, our findings support the notion that there is a measurable, economic incentive to use white space effectively by varying the distances between displayed items. 


\section{Gender}

Gender effects were examined post-hoc and resulted from exploratory data analysis. Overall, gender had a significant impact on the dollar-value estimations made by participants. On average, female participants estimated the value of the items $\$ 57.12$ more than male participants on a $\$ 100$ to $\$ 900$ range used in this study (See Figure 6). Of the online shopping behaviors of the male and female participants in this study, there were no significant differences in previous experience shopping online $(87.7 \%$ male participants and $97.0 \%$ of female participants had previous experience shopping online), weekly hours spent using the internet $(97.6 \%$ of males and $95.5 \%$ of females reported greater than 2 hours of internet usage per week), or frequency of online purchases made. However, there was a significant difference in the monthly amount spent on online shopping by participants of each gender. Of the female participants, $58.2 \%$ self-reported spending between $\$ 1-\$ 50$ shopping online monthly compared to $31.7 \%$ of male participants who self-reported spending in the same range.

Few studies have investigated the effects of website design, and use of white space, on the perception of e-commerce websites by gender. In a relevant study, Cyr and Bonnani (2005) found that the perception of websites differ for men and women, with both groups reporting different levels of satisfaction related to the information, navigation, and visual design of the same e-commerce website. Simon (2000) found significant differences between males and females in reported satisfaction and attributed females' lower responses to them having a more comprehensive information processing strategy compared to males. This attribution is based on findings by a number of other 
studies that indicate that males tend to process visual information selectively rather than process all information comprehensively compared to females, who tend to take a comprehensive approach to information processing (Meyers-Levy, 1989; Meyers-Levy \& Maheswaran, 1991; Meyers-Levy \& Sternthal, 1991). These authors suggests that females are fundamentally different compared to males in the perception of visual stimuli, although it is difficult to discern why the overall design of this experiment yielded gender-differences in price-perception, given that the males and females in this experiment did not differ significantly in terms of their online shopping experience, online shopping frequency, and hours of internet usage. Offline, women are known to make over $70 \%$ of household purchases (US Census, 2000), which suggests that women might have more experience shopping, in general, than do men. Assuming that this holds true for the female participants in this study, it is a possible variable in accounting for why the female participants in this study reported different overall value estimates than the male participants, though the reason for the higher estimates is unknown. Interestingly, the white space distance between objects significantly affected the valueestimation made by male participants but not by female participants. A comparison between a white space distance of 40 px and 120 px revealed a significant difference in the reported value estimates by males, with the items placed 120 px apart valued higher, on average, by $\$ 7.70$, compared to items placed only 40 px apart.

\section{Conclusion}

The effect of visual cues of design is known to affect the online shopping experience, although few studies have attempted to analyze experimentally different 
design factors and their effects. This study assessed the effects of white space using an economic measure. Specifically, white space was manipulated in varying ways participants' subjective perception of price was measured. The findings of this study indicate that the total amount of white space present on websites has no effect on price perception. That is, participants' perception of price was indifferent to the amount of content present. However, the findings of this study support that white space distances between content affected the perception of price for male participants, with greater white space distances yielding a higher estimation of price, suggesting that manipulating the amount of white space between items shown on e-commerce websites could produce impressions of a website's products as high or low in value. 


\section{References}

Ahrens, W. F., \& Bovee, C.L. (1994). Contemporary Advertising (5th ed.). Burr Ridge, IL: Irwin.

Amare, N., \& Manning, A. (2013). A unified theory of information design: Visuals, text and ethics. Amityville, NY: Baywood Publishing Co.

Barnes, S. J., \& Vidgen, R. T. (2002). An integrative approach to the assessment of ecommerce quality. Journal of Electronic Commerce Research, 3(3), 114-127.

Bellman, S., Lohse, G. L., \& Johnson, E. J. (1999). Predictors of online buying behavior. Communications of the ACM, 42(12), 32-38.

Bernard, M., Chaparro, B., \& Thomasson, R. (2000). Finding information on the Web: Does the amount of whitespace really matter. Usability News, 2(1), 1.

Bitner, M. J. (1992). Servicescapes: the impact of physical surroundings on customers and employees. The Journal of Marketing, 56, 57-71.

Bolchini, D., Garzotto, F., \& Sorce, F. (2009). Does branding need web usability? A value-oriented empirical study. In Human-Computer Interaction-INTERACT $2009,652-665$.

Bradshaw, A.C. \& Johari, A. (2000). White Space for Clarity: Suggested Guidelines. In R. E. Griffin, W. Gibbs, and V. Williams (Eds.), Natural Vistas: Visual Literacy and the World Around Us. Selected Readings of the International Visual Literacy Association. Loretto, PA: International Visual Literacy Association

Bradshaw, A. C., \& Johari, A. (2002). Effects of white space in learning via the web. Journal of Educational Computing Research, 26(2), 191-201. 
Burns, D., Venit, S., \& Hansen, R. (1988). The Electronic Publisher. New York, NY: Brady

Carusso, B.R. (1986). Technical Communication. Belmont, CA: Wadsworth.

Casaló, L. V., Flavián, C., \& Guinalíu, M. (2008). The role of satisfaction and website usability in developing customer loyalty and positive word-of-mouth in the ebanking services. International Journal of Bank Marketing, 26(6), 399-417.

Catry, B. (2003). The great pretenders: the magic of luxury goods. Business Strategy Review, 14(3), 10-17.

Chaparro, B. S., Baker, J. R., Shaikh, A. D., Hull, S., \& Brady, L. (2004). Reading online text: A comparison of four whitespace layouts. Usability News, 6(2), 1-7.

Chaparro, B. S., Shaikh, A. D., \& Baker, J. R. (2005). Reading online text with a poor layout: Is performance worse. Usability News, 7(1), 1-4.

Chen, Y. T., Cai, D., Huang, H., \& Kuo, J. (2003). An evaluation model for graphic design works. Proceedings of Sixth Asian Design Conference, October 2003, Tsukuba, Japan (pp. 14-17).

Cialdini Robert, B. (1993). Influence: Science and practice. New York, NY: Harper Collins.

Cunliffe, D. (2000). Developing usable Web sites-a review and model. Internet Research, 10(4), 295-308.

Cyr, D., \& Bonanni, C. (2005). Gender and website design in e-business. International Journal of Electronic Business, 3(6), 565-582. 
Dalal, N. P., Quible, Z., \& Wyatt, K. (2000). Cognitive design of home pages: an experimental study of comprehension on the World Wide Web. Information Processing \& Management, 36(4), 607-621.

D'angelo, J., \& Little, S. K. (1998). Successful Web pages: what are they and do they exist?. Information Technology and Libraries, 17(2), 71-81.

Davis, F. D. (1989). Perceived usefulness, perceived ease of use, and user acceptance of information technology. MIS Quarterly, 13(3), 319-340.

Dickson, P.R, \& Sawyer, A.G. (1990). The price knowledge and search of supermarket shoppers. Journal of Marketing, 54, 42-53.

Donovan, R.J., \& Rossiter, J.R. (1982). Store atmosphere: an environmental psychology approach. Journal of Retailing, 58(1), 34-57.

Drewniany, B.L., \& Jewler, A. J. (2011), Creative Strategy in Advertising, (10th ed.). Belmont, CA: Wadsworth.

Elias, N. (1982) The Civilizing Process. State Formation and Civilization. Oxford: Basil Blackwell.

Eroglu, S. A., Machleit, K. A., \& Davis, L. M. (2001). Atmospheric qualities of online retailing: a conceptual model and implications. Journal of Business research, 54(2), 177-184.

Faul, F., Erdfelder, E., Lang, A. G., \& Buchner, A. (2007). G* Power 3: A flexible statistical power analysis program for the social, behavioral, and biomedical sciences. Behavior research methods, 39(2), 175-191. 
Felici, J., \& Nace, T. (1987). Desktop publishing skills: a primer for typesetting with computer and laser printer. Reading, MA: Addison-Wesley

Finke, G. D. (2001). White Graphics: The Power of White in Graphic Design. Rockport Pub.

Fogg, B. J., Soohoo, C., Danielson, D. R., Marable, L., Stanford, J., \& Tauber, E. R. (2003, June). How do users evaluate the credibility of Web sites?: a study with over 2,500 participants. Proceedings of the 2003 conference on Designing for user experiences (pp. 1-15). ACM.

Gabor, A., \& Granger, C. W. (1961). On the price consciousness of consumers. Applied Statistics, 170-188.

Gerstner, E. (1985). Do higher prices signal higher quality?. Journal of marketing research, 209-215.

Hoque, A. Y., \& Lohse, G. L. (1999). An Information Search Cost Perspective for Designing Interface for Electronic Commerce. Journal of Marketing Research 36(3), 387-394.

Huang, J. H., \& Yang, T. K. (2011). The impacts of homepage screen density on website evaluations: The moderating role of personality type. Social Behavior and Personality: an international journal, 39(3), 381-390.

International Organization for Standardization. (1998). ISO 9241-11: Ergonomic Requirements for Office Work with Visual Display Terminals (VDTs): Part 11: Guidance on Usability. 
Kalakota, R., \& Whinston, A.B. (1997). Electronic Commerce: A Manager's Guide. Reading, MA: Addison-Wesley

Krages, B. (2005). Photography: The art of composition. New York, NY: Allworth Press.

Levine, K. (2000). Do Nothing. Critique Magazine (Summer), 1. Retrieved from http://www.icograda.org/feature/current/articles12.htm.

Lichtenstein, D. R., \& Burton, S. (1989). The relationship between perceived and objective price-quality. Journal of Marketing Research, 429-443.

Lo, B. W., \& Gong, P. (2005). Cultural impact on the design of e-commerce websites: Part I- Site format and layout. Issues in Information Systems, 6(2), 182-189.

Lynn, M. (1991). Scarcity effects on value: A quantitative review of the commodity theory literature. Psychology \& Marketing, 8(1), 43-57.

Munnukka, J. (2008). Customers' purchase intentions as a reflection of price perception. The Journal of Product and Brand Management, 17(3), 188-196.

McKinney, L. N. (2004). Creating a satisfying internet shopping experience via atmospheric variables. International Journal of Consumer Studies, 28(3), 268283.

Mehrabian, A., \& Russell, J. A. (1974). An approach to environmental psychology (Vol. 11). Cambridge, MA: MIT Press.

Meyers-Levy, J. (1989). Gender differences in information processing: A selectivity interpretation. In Cafferata, P., and Tybout, A.M. (Eds.), Cognitive and Affective Responses to Advertising (pp. 219-260). Lexington, MA: Lexington Books. 
Meyers-Levy, J., \& Maheswaran, D. (1991). Exploring differences in males' and females' processing strategy. Journal of Consumer Research, 18, 63-70.

Meyers-Levy, J., \& Sternthal, B. (1991). Gender differences in the use of message cues and judgements. Journal of Marketing Research, 28, 84-96.

Monroe, K. B. (1973). Buyers' subjective perceptions of price. Journal of Marketing Research, $10,70-80$.

Morgan, E. L. (1999). Design elements for great web pages: Readability, browsability, searchability plus assistance. Raleigh, NC. Retrieved from http://www. lib. ncsu. edu/staff/morgan/design.

Morris, R.T., \& Bronson, C.S. (1969). The chaos in competition indicated by consumer reports. Journal of Marketing, 3, 26-43.

Mortelmans, D. (2005). Visualizing emptiness. Visual anthropology, 18(1), 19-45.

Mummalaneni, V. (2005). An empirical investigation of web site characteristics, consumer emotional states and on-line shopping behaviors. Journal of Business Research, 58(4), 526-532.

Nielsen, J., \& Gilutz, S. (2003). Usability return on investment. Fremont, CA: Nielsen Norman Group. Retrieved from http://csi.ufs.ac.za/resres/files/Nielsen2.pdf Okonkwo, U. (2005). Can the luxury fashion brand store atmosphere be transferred to the internet? Retrieved from http://www. brandchannel. com/images/papers/269_Lux_Goods_Online.pdf. 
Oxenfeldt, A. R. (1950). Consumer knowledge: Its measurement and extent. The Review of Economics and Statistics, 32(4), 300-314.

Parker, R. C., \& Berry, P. (1998). Looking good in print. Chapel Hill, NC: Ventana Press.

Petterson, R. (1993) Visual Information (2nd ed.). Englewood Cliffs, NJ: Educational Technology Publications.

Pracejus, J. W., Olsen, G. D., \& O’Guinn, T. C. (2006). How nothing became something: white space, rhetoric, history, and meaning. Journal of Consumer Research, 33(1), 82-90.

Rau, P. L. P., Gao, Q., \& Liu, J. (2007). The effect of rich web portal design and floating animations on visual search. International Journal of Human-Computer Interaction, 22(3), 195-216.

Robertson, K. (1994). On white space/when less is more. Looking Closer: Critical Writings on Graphic Design, 1, 61.

Rosenholtz, R., Li, Y., Mansfield, J., \& Jin, Z. (2005). Feature congestion: a measure of display clutter. In Proceedings of the SIGCHI conference on Human factors in computing systems (pp. 761-770). ACM.

Simon, S. J. (2000). The impact of culture and gender on web sites: an empirical study. ACM SIGMIS Database, 32(1), 18-37.

Smith, T. J. (2008). Senior citizens and e-commerce websites: The role of perceived usefulness, perceived ease of use, and web site usability. Informing Science: International Journal of an Emerging Transdiscipline, 11, 59-83. 
Spool, J. M., Scanlon, T., Schroeder, W., Snyder, C., \& DeAngelo, T. (1997). Web Site Usability: A Designer's Guide. San Francisco, CA: Morgan Kaufmann Publishers.

Staggers, N. (1993). Impact of screen density on clinical nurses' computer task performance and subjective screen satisfaction. International Journal of ManMachine Studies, 39(5), 775-792.

Thüring, M., Hannemann, J., \& Haake, J. M. (1995). Hypermedia and cognition: Designing for comprehension. Communications of the ACM, 38(8), 57-66.

Truchard, A., \& Katz-Haas, R. (1998). Ten guidelines for user-centered web design. Usability Interface, 5(1), 12-13.

U.S. Census (2000). U.S. Census Data 2000. Retrieved from http://www. census.gov/econ/www/retmenu.html.

U.S. Census Bureau Retail Indicators Branch (2013). Estimated quarterly U.S. retail sales (adjusted): Total and e-commerce. Retrieved from http://www.census.gov/retail/mrts/www/data/excel/tsadjustedsales.xls

Wang, Y. D., \& Emurian, H. H. (2005). Trust in e-commerce: consideration of interface design factors. Journal of Electronic Commerce in Organizations (JECO), 3(4), 42-60.

White, A. W. (2011). The elements of graphic design. New York, NY: Allworth Press. White, D., \& Ariguzo, G. (2011). A Time-Series Analysis of US E-Commerce Sales. Review of Business Research, 11(4), 134-140.Wickens, C. D., \& Carswell, C. M. (1995). The proximity compatibility principle: Its psychological foundation 
and relevance to display design. Human Factors: The Journal of the Human Factors and Ergonomics Society, 37(3), 473-494. 
Appendix A

\section{Samples of Retail Furniture Websites}

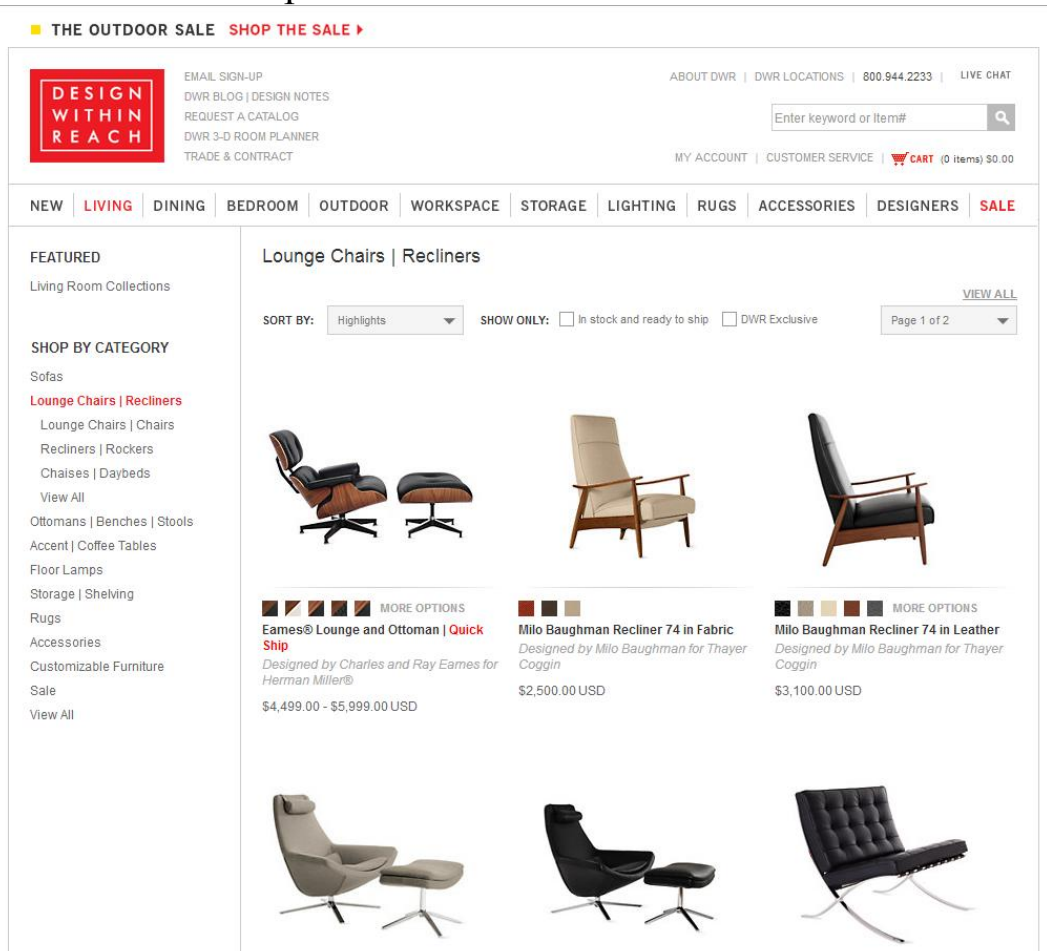

Figure 9. Website of Design Within Reach, furniture retailer. Reprinted from Lounge Chairs and Recliners, In Design Within Reach, n.d., Retrieved February 27, 2013 from http://www.dwr.com/category/living/chairsrecliners.do?nType $=2$.

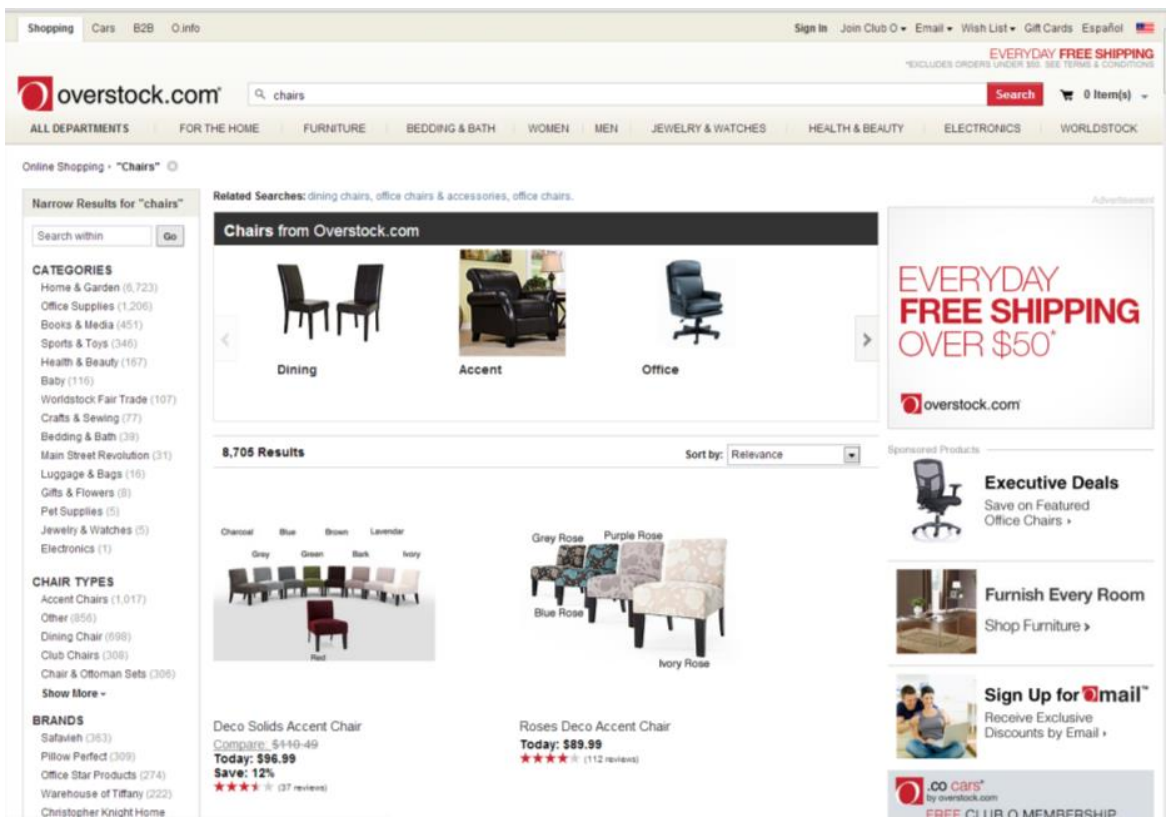

Figure 10. Website of Overstock.com, general retailer. Reprinted from Chairs, In Overstock.com, n.d., Retrieved February 27, 2013 from http://www.overstock.com/Home-Garden/Chairs/2737/subcat.html?sort=Top+Sellers. 


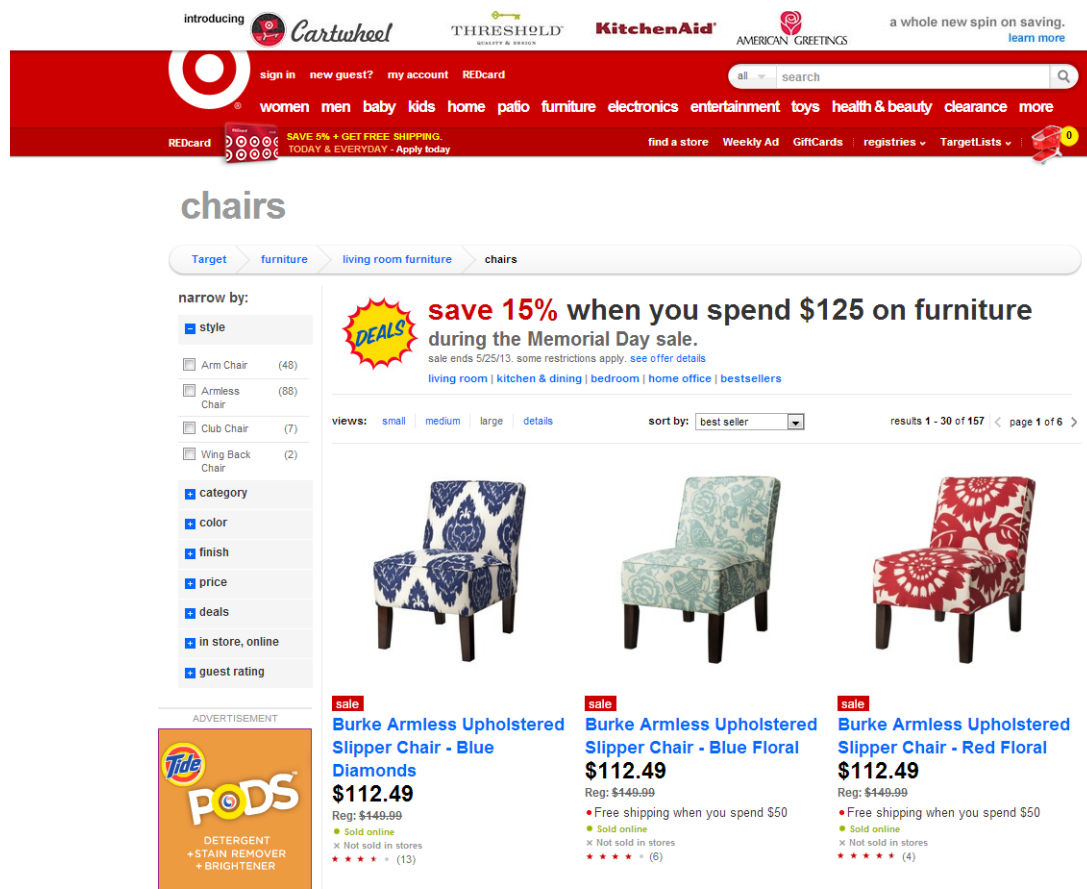

Figure 11. Website of Target general retailer. Reprinted from Chairs, in Target, n.d., Retrieved May 10, 2013 from http://www.target.com/c/chairs-living-room-furniture/-/N-5xtlz\#?lnk=lnav_shop categories_2.

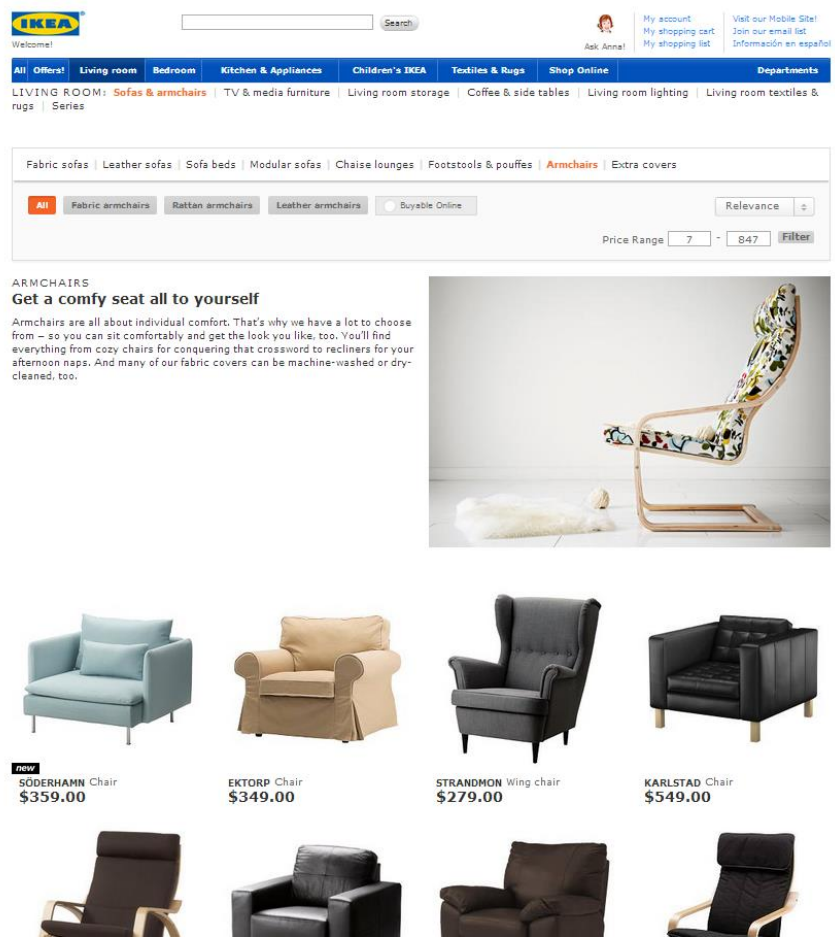

Figure 12. Website of Ikea, furniture retailer. Reprinted from Sofas and Armchairs, in Ikea, n.d., Retrieved May 10, 2013 from http://www.ikea.com/us/en/catalog/categories/departments/living_room/16239/. 
Appendix B

Image Sets Used As Stimuli

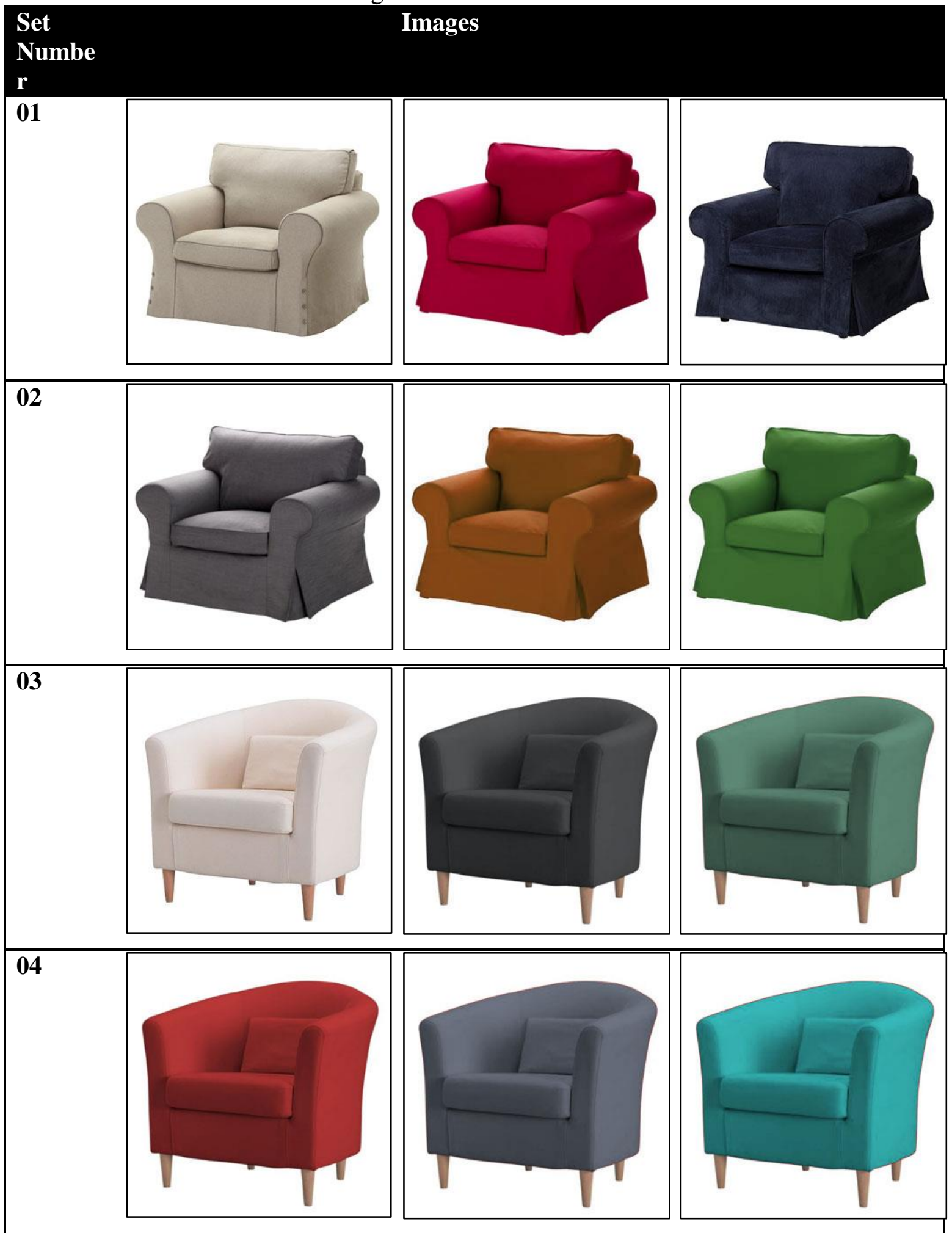




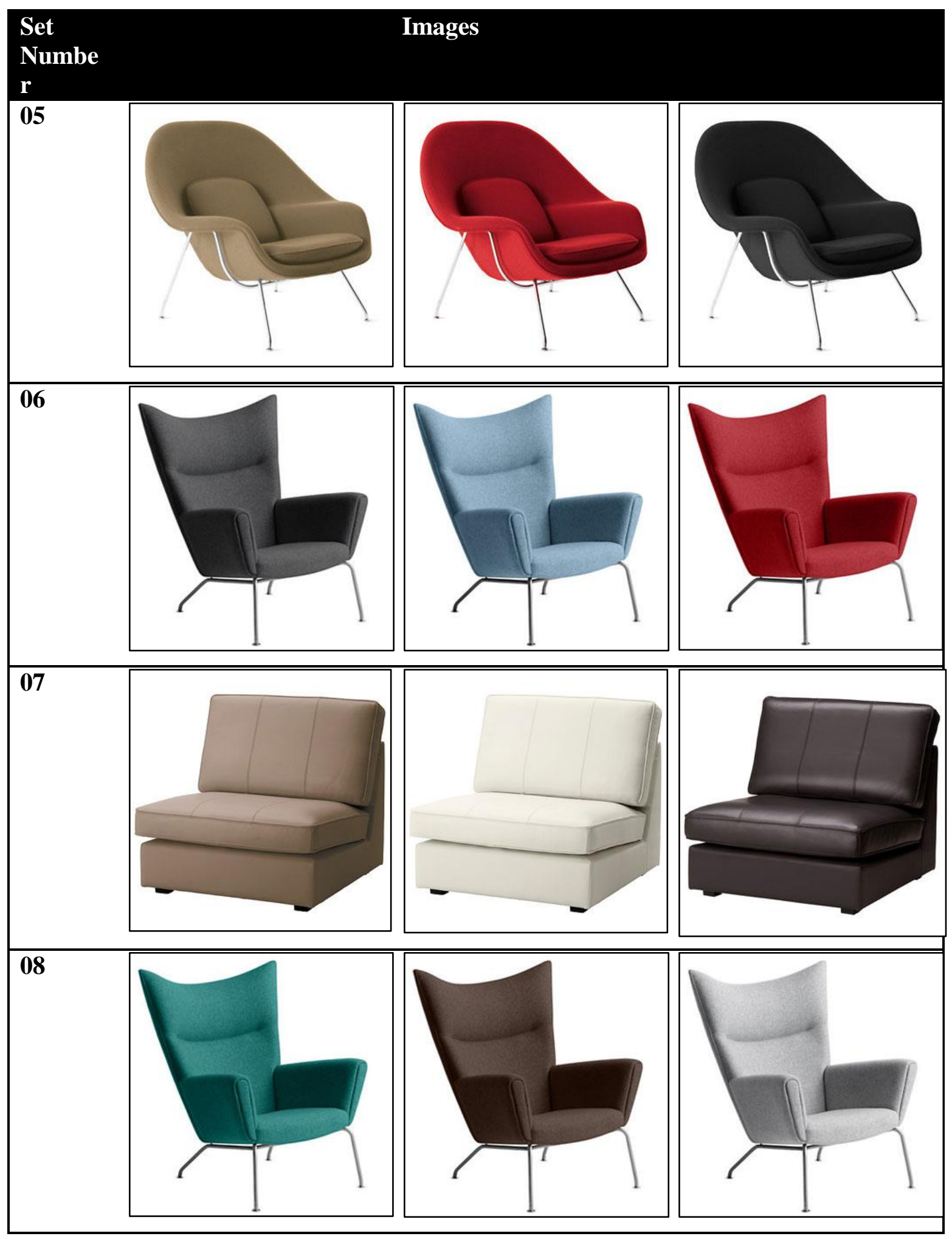




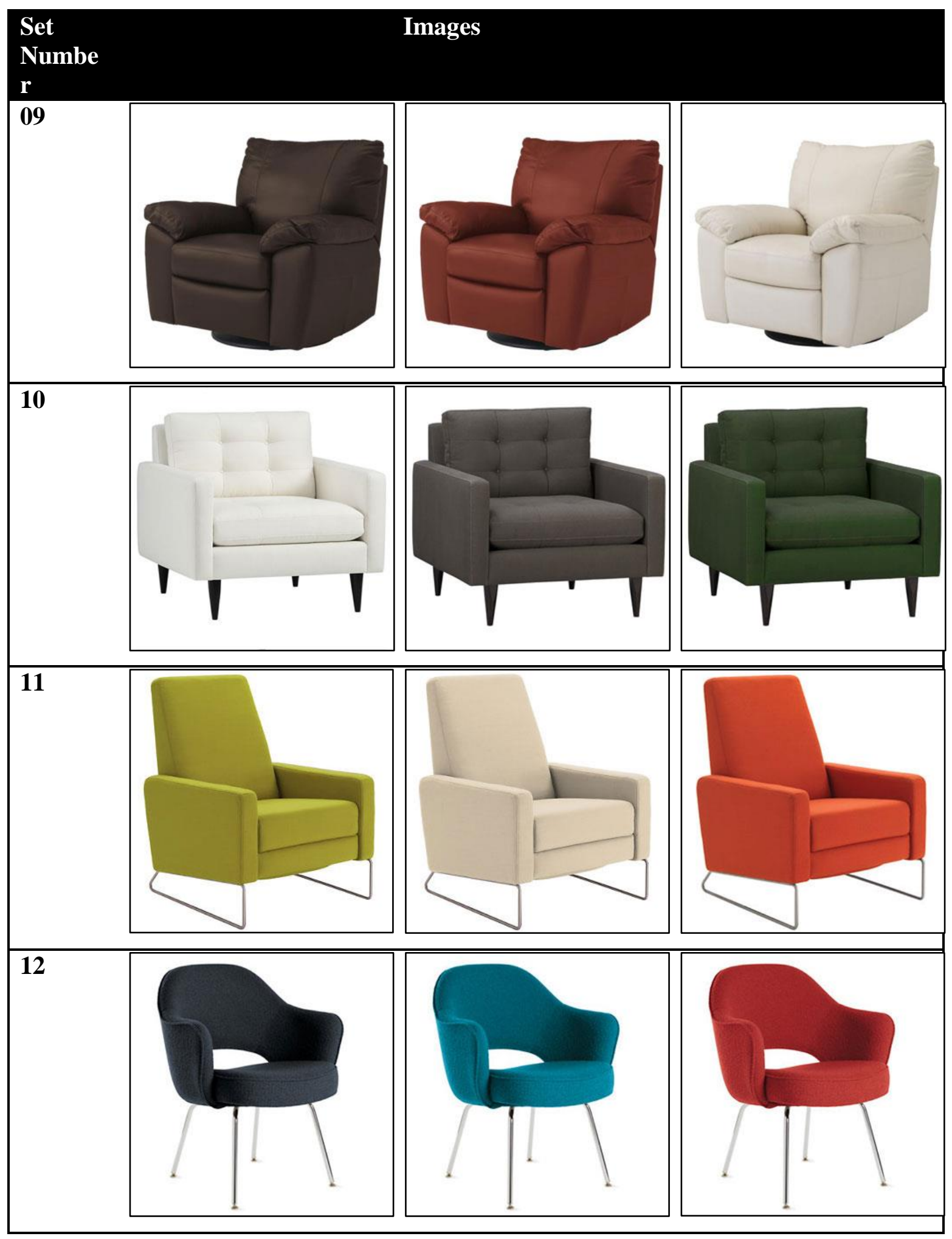




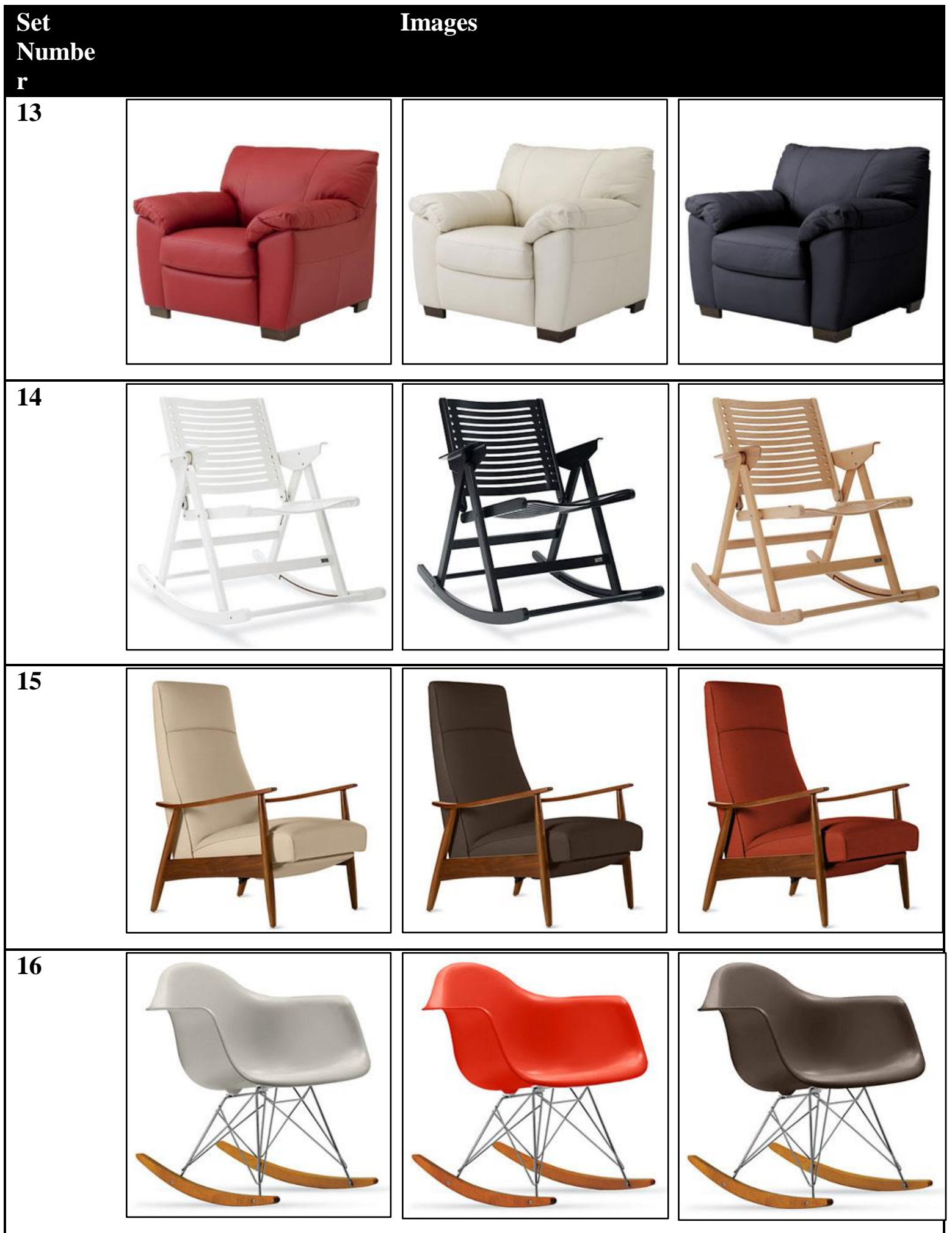




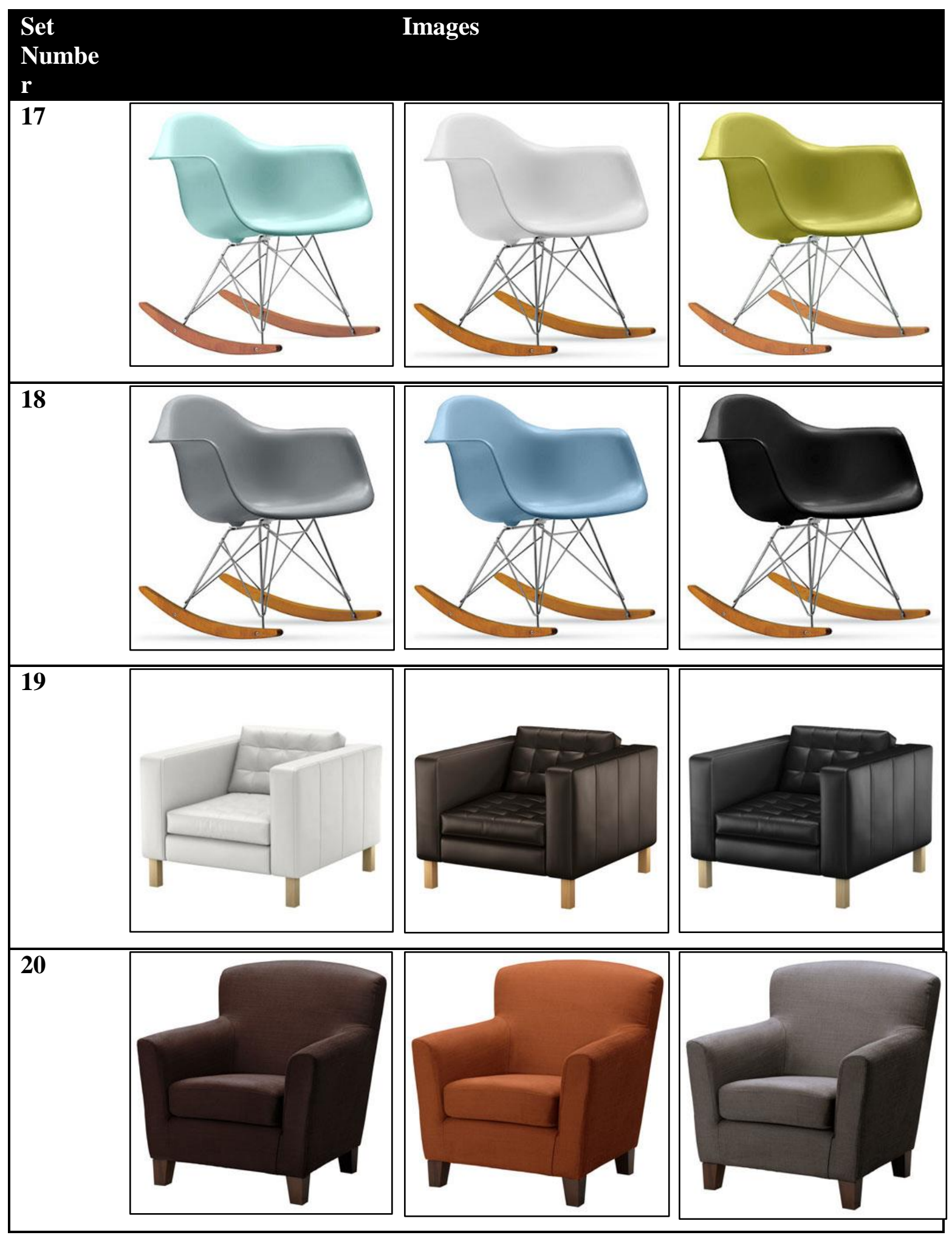


Appendix C

Stimuli at Near (40px), Medium (80 px) and Far (120px) Distances of White Space

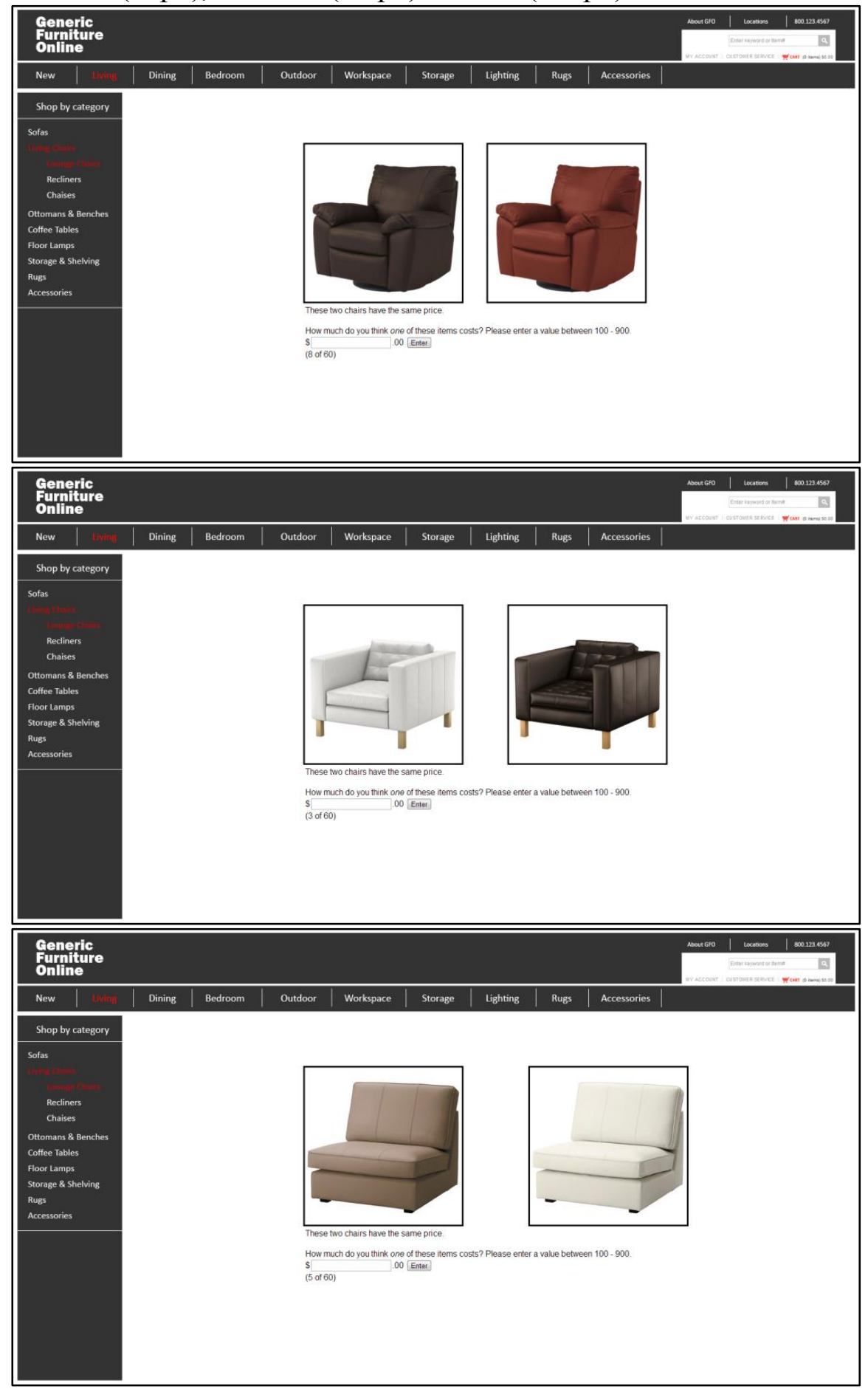

Figure 13. Sample stimuli in the 2 -image condition presented at near (40 px), medium (80 px), and far (120 px) distances. 


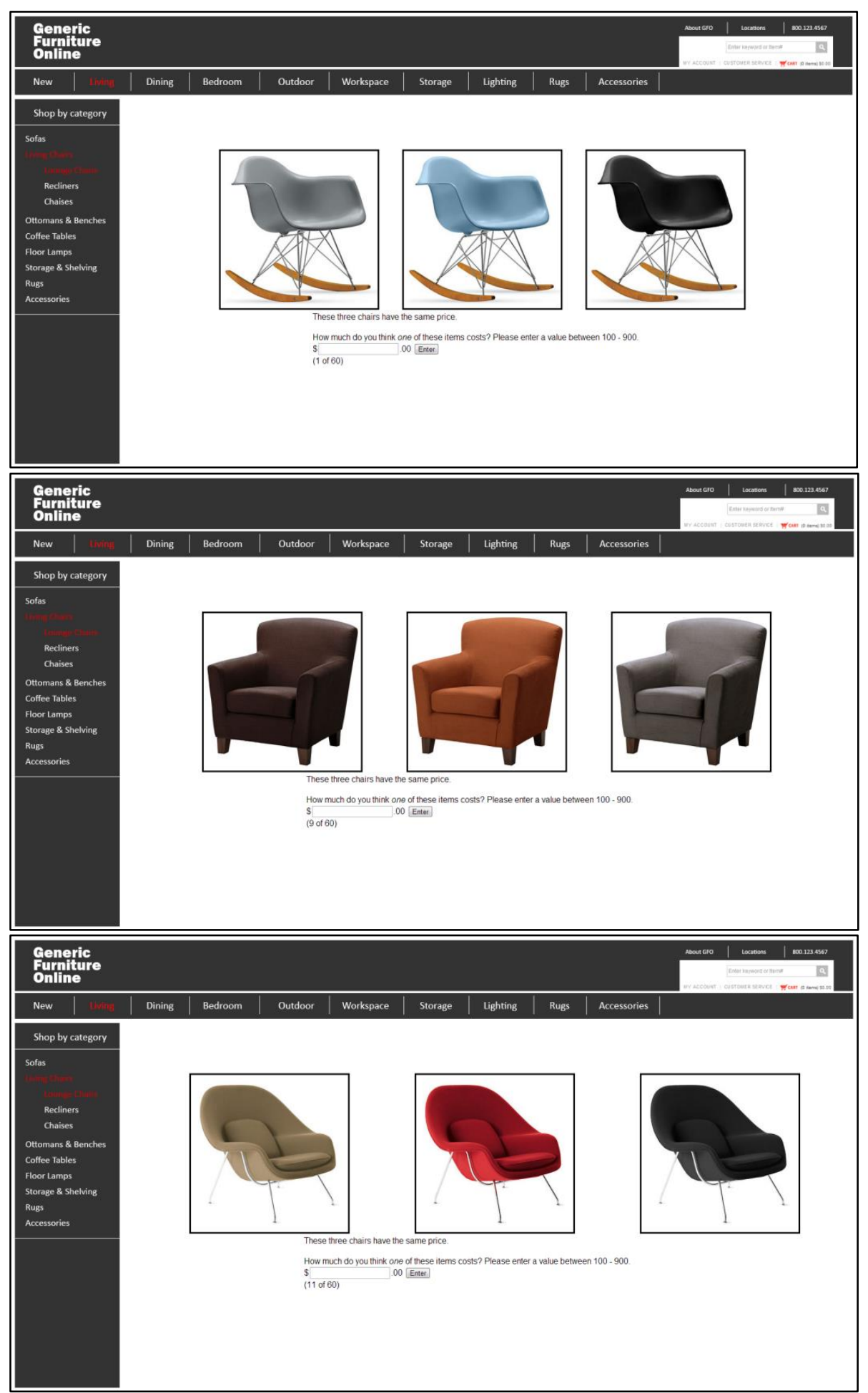

Figure 14. Sample stimuli in the 3-image condition presented at near (40 px), medium (80 px), and far (120 px) distances. 
Appendix D

Demographic Questionnaire

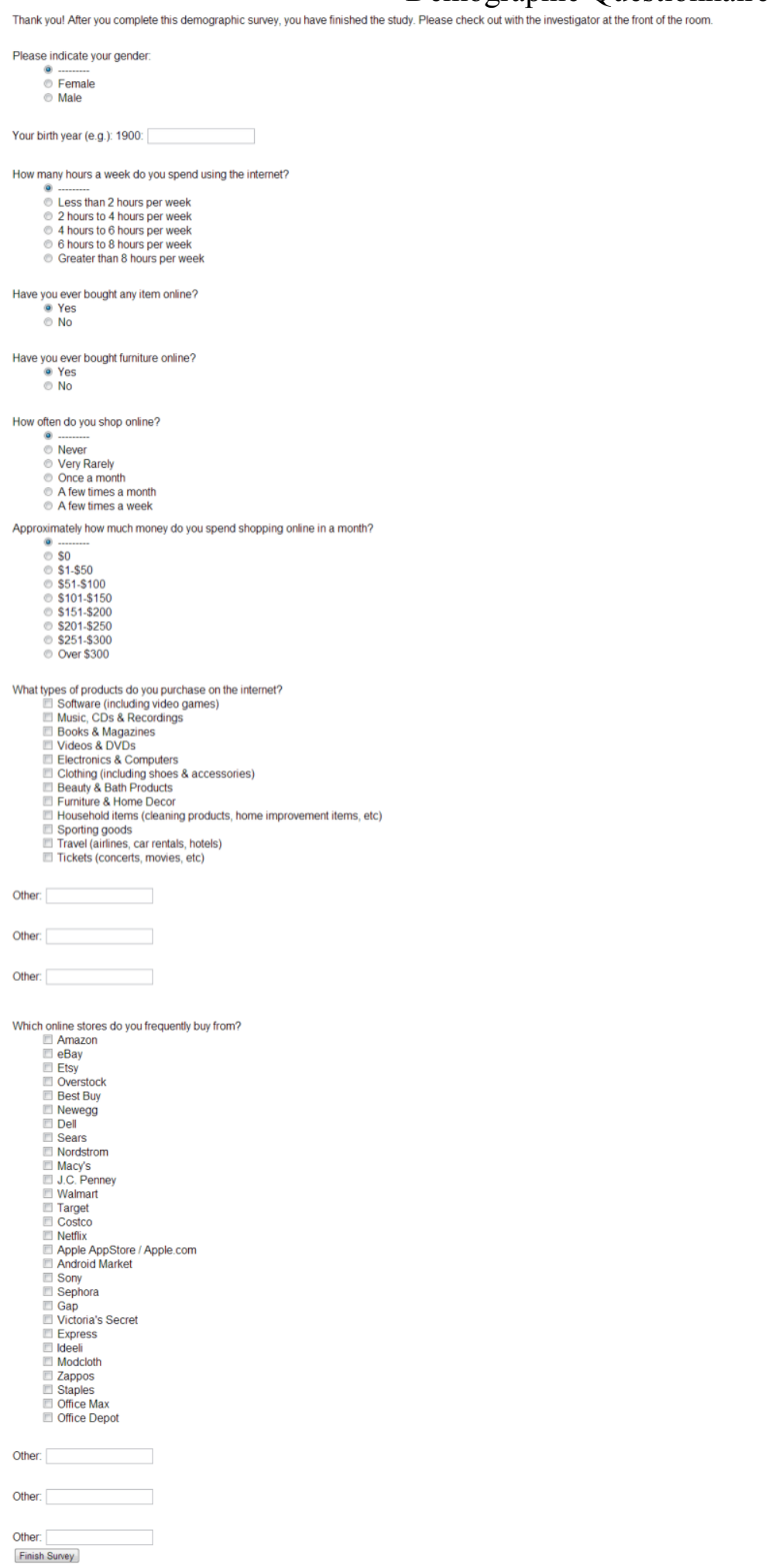




\section{Appendix E \\ Agreement to Participate in Research \\ Consent Form \\ Agreement to Participate in Research}

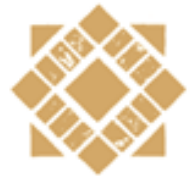

San José State

UNIVERSITY

Department of Psychology

DMH 157

One Washington Square

San Jose. CA 95192-1020

Volce: $408-924-5600$

www psych.slsu.ed
The Calformin Stats Lruivenith:Chaneellor', Olfes Bakernfeld, Charnel blankh, Cries Dominnuer Hall, Eav! Bav, Freno,

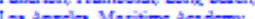
Los Anzela, Mastime Aesdems; Sacraments, San Bernardins, Sen Diero, San Franeives, Sen Jeac, Sen Lui Obivgo, San Manse, Senoma.

\section{Responsible Investigator: Sin Lee Loh \& Sean Laraway}

Title of Study: Consumer Perceptions of Price and Value in E-Commerce

1. You have been asked to participate in a study investigating the perception of price and value when shopping on the web.

2. You will be asked to view an e-commerce website selling chairs. You are required to estimate the amount ONE chair on the screen costs, and type in the amount in the text box provided. At the conclusion of the study, you will be asked some basic demographic questions.

3. Absolute anonymity of data and records will be maintained. Although the results of this study may be published, no disclosure of data that will identify specific participants stored after the conclusion of the study.

4. Potential risks, discomforts, or adverse effects on your physical, mental, and emotional well-being are minimal in this study.

5. In return for participation in this study, you will earn course credit from your instructor. This study should take no more than 45 minutes.

6. Questions about this research may be addressed to Sin Lee Loh at sinlee@gmail.com. Complaints about the research may be presented to Ronald Rogers, PhD, Chair of the Psychology Department, (408) 924-5652. Questions about a research subjects' rights, or research-related injury may be presented to Pamela Stacks, Ph.D., Associate Vice President of Graduate Studies and Research, at (408) 924-2427.

7. No service of any kind, to which you are otherwise entitled, will be lost or jeopardized if you choose not to participate in this study.

8. Your consent is being given voluntarily. If you do not wish to participate, or feel uncomfortable at any time, you may discontinue participation without consequence. If you decide to participate in the study, you are free to withdraw at any point during the study without any negative effect on your relations with San Jose State University.

9. At the time you sign this consent form, you will receive a copy of it for your records, signed and dated by the investigator.

The signature of a subject on this document indicates agreement to participate in the study.

The signature of a researcher on this document indicates agreement to include the above named subject in the research and attestation that the subject has been fully informed of his or her rights.

$\begin{array}{lll}\text { Participant's Signature } & \text { Date } \\ \text { Investigator's Signature } & \text { Date }\end{array}$




\section{Appendix F \\ Raw Data}

\begin{tabular}{|c|c|c|c|c|c|c|c|c|c|c|c|}
\hline P.ID & $\begin{array}{l}\text { Group } \\
\text { Num }\end{array}$ & AvgN & AvgM & $\operatorname{AvgF}$ & gender & birth_year & $\begin{array}{l}\text { shopped_ } \\
\text { online }\end{array}$ & $\begin{array}{l}\text { furniture_ } \\
\text { online }\end{array}$ & $\begin{array}{l}\text { shop_online__ } \\
\text { freq }\end{array}$ & $\begin{array}{l}\text { shop_online_ } \\
\text { spend }\end{array}$ & $\begin{array}{l}\text { Internet } \\
\text { _hr_week }\end{array}$ \\
\hline 4 & 2 & 511.75 & 498.5 & 514.75 & $\mathrm{~m}$ & 1994 & 0 & 0 & "Very Rarely" & $\$ 51-\$ 100$ & "4-6" \\
\hline 6 & 2 & 177.5 & 190 & 197.5 & $\mathrm{~m}$ & 1994 & 1 & 0 & $\begin{array}{l}\text { "A few times } \\
\text { a month" }\end{array}$ & $\$ 201-\$ 250$ & ">8" \\
\hline 8 & 2 & 371.75 & 382.2 & 368 & $\mathrm{f}$ & 1993 & 1 & 0 & $\begin{array}{l}\text { "Once a } \\
\text { month" }\end{array}$ & $\$ 51-\$ 100$ & "4-6" \\
\hline 10 & 2 & 488.7 & 434.95 & 417.45 & $\mathrm{f}$ & 1993 & 1 & 0 & "Very Rarely" & $\$ 1-\$ 50$ & "4-6" \\
\hline 12 & 2 & 243 & 235.5 & 252.5 & $\mathrm{f}$ & 1993 & 1 & 0 & $\begin{array}{l}\text { "A few times } \\
\text { a month" }\end{array}$ & $\$ 1-\$ 50$ & ">8" \\
\hline 14 & 2 & 247.45 & 260 & 262 & $\mathrm{~m}$ & 1994 & 0 & 0 & "Very Rarely" & $\$ 1-\$ 50$ & "6-8" \\
\hline 16 & 2 & 393.5 & 430.75 & 357.75 & $\mathrm{f}$ & 1993 & 1 & 0 & "Very Rarely" & $\$ 1-\$ 50$ & "6-8" \\
\hline 26 & 2 & 385 & 387.5 & 387.5 & $\mathrm{f}$ & 1994 & 1 & 0 & "Very Rarely" & $\$ 1-\$ 50$ & ">8" \\
\hline 28 & 2 & 280.75 & 322.25 & 304 & $\mathrm{f}$ & 1994 & 1 & 0 & "Very Rarely" & $\$ 1-\$ 50$ & ">8" \\
\hline 30 & 2 & 308.65 & 340.75 & 351.65 & $\mathrm{f}$ & 1994 & 1 & 0 & "Very Rarely" & $\$ 0$ & "2-4" \\
\hline 32 & 2 & 358.25 & 355 & 372.5 & $\mathrm{~m}$ & 1994 & 1 & 0 & $\begin{array}{l}\text { "A few times } \\
\text { a month" }\end{array}$ & $\$ 101-\$ 150$ & ">8" \\
\hline 34 & 2 & 723.75 & 691.25 & 682.5 & $\mathrm{f}$ & 1991 & 1 & 0 & $\begin{array}{l}\text { "Once a } \\
\text { month" }\end{array}$ & $\$ 51-\$ 100$ & "4-6" \\
\hline 36 & 2 & 449.9 & 436.05 & 449.1 & $\mathrm{f}$ & 1993 & 1 & 0 & $\begin{array}{l}\text { "Once a } \\
\text { month" }\end{array}$ & $\$ 51-\$ 100$ & ">8" \\
\hline 38 & 2 & 206.25 & 235.5 & 243.75 & $\mathrm{f}$ & 1994 & 1 & 0 & $\begin{array}{l}\text { "Once a } \\
\text { month" }\end{array}$ & $\$ 1-\$ 50$ & ">8" \\
\hline 40 & 2 & 249.75 & 220.25 & 222.25 & $\mathrm{f}$ & 1993 & 1 & 0 & $\begin{array}{l}\text { "Once a } \\
\text { month" }\end{array}$ & $\$ 1-\$ 50$ & ">8" \\
\hline 42 & 2 & 307.75 & 316.15 & 279.3 & $\mathrm{f}$ & 1992 & 1 & 0 & "Very Rarely" & $\$ 1-\$ 50$ & "4-6" \\
\hline 44 & 2 & 300 & 295 & 315 & $\mathrm{~m}$ & 1994 & 1 & 0 & "Very Rarely" & $\$ 1-\$ 50$ & ">8" \\
\hline 46 & 2 & 271.5 & 278.2 & 284.05 & $\mathrm{f}$ & 1994 & 1 & 0 & $\begin{array}{l}\text { "Once a } \\
\text { month" }\end{array}$ & $\$ 1-\$ 50$ & ">8" \\
\hline 48 & 2 & 148.4 & 147 & 151.25 & $\mathrm{~m}$ & 1993 & 1 & 0 & $\begin{array}{l}\text { "Once a } \\
\text { month" }\end{array}$ & $\$ 1-\$ 50$ & "4-6" \\
\hline 50 & 2 & 293.55 & 237 & 318.1 & $\mathrm{~m}$ & 1992 & 0 & 0 & $\begin{array}{l}\text { "Once a } \\
\text { month" }\end{array}$ & $\$ 51-\$ 100$ & ">8" \\
\hline 52 & 2 & 250 & 261.25 & 300 & $\mathrm{f}$ & 1994 & 1 & 0 & "Very Rarely" & $\$ 51-\$ 100$ & ">8" \\
\hline 54 & 2 & 248.25 & 229.25 & 231.35 & $\mathrm{f}$ & 1994 & 1 & 0 & "Very Rarely" & $\$ 1-\$ 50$ & ">8" \\
\hline 58 & 2 & 211.25 & 212.75 & 221 & $\mathrm{~m}$ & 1994 & 1 & 1 & $\begin{array}{l}\text { "A few times } \\
\text { a month" }\end{array}$ & $\$ 51-\$ 100$ & ">8" \\
\hline 60 & 2 & 308.25 & 296.5 & 315.25 & $\mathrm{f}$ & 1994 & 1 & 0 & $\begin{array}{l}\text { "Once a } \\
\text { month" }\end{array}$ & $\$ 1-\$ 50$ & ">8" \\
\hline 62 & 2 & 343.5 & 348 & 337.5 & $\mathrm{f}$ & 1994 & 1 & 0 & "Very Rarely" & $\$ 1-\$ 50$ & ">8" \\
\hline 64 & 2 & 301.5 & 291 & 328.5 & $\mathrm{~m}$ & 1994 & 1 & 0 & "Very Rarely" & $\$ 1-\$ 50$ & ">8" \\
\hline 66 & 2 & 297.5 & 297.5 & 287.5 & $\mathrm{f}$ & 1994 & 1 & 0 & $\begin{array}{l}\text { "A few times } \\
\text { a month" }\end{array}$ & $\$ 1-\$ 50$ & ">8" \\
\hline 68 & 2 & 197.45 & 181.3 & 197.85 & $\mathrm{~m}$ & 1990 & 1 & 1 & $\begin{array}{l}\text { "Once a } \\
\text { month" }\end{array}$ & $\$ 151-\$ 200$ & "6-8" \\
\hline 70 & 2 & 249.25 & 251 & 251.25 & f & 1993 & 1 & 0 & "Very Rarely" & $\$ 1-\$ 50$ & "2-4" \\
\hline 72 & 2 & 303.25 & 351.5 & 320.75 & $\mathrm{f}$ & 1993 & 1 & 0 & $\begin{array}{l}\text { "A few times } \\
\text { a month" }\end{array}$ & $\$ 51-\$ 100$ & "6-8" \\
\hline 74 & 2 & 487.45 & 501.75 & 488.5 & $\mathrm{~m}$ & 1991 & 0 & 0 & "Very Rarely" & $\$ 0$ & "2" \\
\hline
\end{tabular}




\begin{tabular}{|c|c|c|c|c|c|c|c|c|c|c|c|}
\hline 76 & 2 & 274 & 274.45 & 268.2 & $\mathrm{f}$ & 1994 & 1 & 0 & $\begin{array}{l}\text { "A few times } \\
\text { a month" }\end{array}$ & $\$ 51-\$ 100$ & ">8" \\
\hline 78 & 2 & 247.3 & 234.95 & 224.6 & $\mathrm{~m}$ & 1994 & 1 & 0 & $\begin{array}{l}\text { "A few times } \\
\text { a month" }\end{array}$ & $\$ 51-\$ 100$ & "4-6" \\
\hline 80 & 2 & 146.5 & 141.4 & 142.75 & $\mathrm{~m}$ & 1994 & 1 & 0 & $\begin{array}{l}\text { "A few times } \\
\text { a month" }\end{array}$ & $\$ 51-\$ 100$ & "6-8" \\
\hline 82 & 2 & 391.75 & 401.25 & 402.25 & $\mathrm{f}$ & 1994 & 1 & 0 & "Very Rarely" & $\$ 1-\$ 50$ & ">8" \\
\hline 84 & 2 & 187.75 & 186.75 & 191.25 & $\mathrm{~m}$ & 1994 & 1 & 0 & "Very Rarely" & $\$ 51-\$ 100$ & ">8" \\
\hline 86 & 2 & 277.25 & 262 & 277.25 & $\mathrm{f}$ & 1993 & 1 & 0 & "Very Rarely" & $\$ 1-\$ 50$ & "4-6" \\
\hline 90 & 2 & 557.5 & 525 & 577.5 & $\mathrm{~m}$ & 1993 & 1 & 0 & $\begin{array}{l}\text { "Once a } \\
\text { month" }\end{array}$ & $\$ 1-\$ 50$ & "6-8" \\
\hline 92 & 2 & 403.75 & 398.25 & 398.5 & $\mathrm{f}$ & 1994 & 1 & 0 & "Very Rarely" & $\$ 1-\$ 50$ & "4-6" \\
\hline 94 & 2 & 310.45 & 324.75 & 329.2 & $\mathrm{~m}$ & 1994 & 1 & 0 & "Very Rarely" & $\$ 0$ & ">8" \\
\hline 96 & 2 & 240.25 & 242.25 & 219.25 & $\mathrm{f}$ & 1993 & 1 & 1 & $\begin{array}{l}\text { "A few times } \\
\text { a month" }\end{array}$ & $\$ 51-\$ 100$ & "4-6" \\
\hline 98 & 2 & 132 & 145.5 & 133.45 & $\mathrm{~m}$ & 1993 & 1 & 0 & "Very Rarely" & $\$ 51-\$ 100$ & ">8" \\
\hline 100 & 2 & 530 & 557 & 559.25 & $\mathrm{f}$ & 1993 & 1 & 0 & "Very Rarely" & $\$ 0$ & "4-6" \\
\hline 102 & 2 & 362.25 & 325.5 & 343.75 & $\mathrm{f}$ & 1994 & 1 & 0 & $\begin{array}{l}\text { "Once a } \\
\text { month" }\end{array}$ & $\$ 1-\$ 50$ & "4-6" \\
\hline 104 & 2 & 220 & 217.5 & 233 & $\mathrm{~m}$ & 1993 & 1 & 0 & $\begin{array}{l}\text { "A few times } \\
\text { a month" }\end{array}$ & $\$ 51-\$ 100$ & ">8" \\
\hline 106 & 2 & 432.5 & 471 & 432.25 & $\mathrm{f}$ & 1993 & 1 & 0 & $\begin{array}{l}\text { "Once a } \\
\text { month" }\end{array}$ & $\$ 1-\$ 50$ & "2-4" \\
\hline 108 & 2 & 293.5 & 301 & 298.7 & $\mathrm{f}$ & 1994 & 1 & 0 & "Very Rarely" & $\$ 0$ & "6-8" \\
\hline 110 & 2 & 379.05 & 391.4 & 401.6 & $\mathrm{f}$ & 1993 & 1 & 0 & $\begin{array}{l}\text { "Once a } \\
\text { month" }\end{array}$ & $\$ 51-\$ 100$ & ">8" \\
\hline 112 & 2 & 262.75 & 286.5 & 287.65 & $\mathrm{f}$ & 1992 & 1 & 0 & $\begin{array}{l}\text { "A few times } \\
\text { a week" }\end{array}$ & $\$ 101-\$ 150$ & ">8" \\
\hline 114 & 2 & 491.05 & 552.1 & 469.15 & $\mathrm{f}$ & 1990 & 1 & 0 & "Very Rarely" & $\$ 0$ & "2" \\
\hline 116 & 2 & 121 & 122.75 & 134.75 & $\mathrm{~m}$ & 1994 & 1 & 0 & "Very Rarely" & $\$ 0$ & ">8" \\
\hline 118 & 2 & 396.5 & 418.7 & 391.5 & $\mathrm{~m}$ & 1994 & 1 & 0 & "Very Rarely" & $\$ 1-\$ 50$ & ">8" \\
\hline 120 & 2 & 236.5 & 249.5 & 251.25 & $\mathrm{f}$ & 1994 & 1 & 0 & Never & $\$ 0$ & "6-8" \\
\hline 122 & 2 & 610 & 630 & 635 & $\mathrm{f}$ & 1993 & 1 & 0 & "Very Rarely" & $\$ 1-\$ 50$ & ">8" \\
\hline 124 & 2 & 327.45 & 321.25 & 332.45 & $\mathrm{f}$ & 1980 & 1 & 1 & $\begin{array}{l}\text { "A few times } \\
\text { a month" }\end{array}$ & $\$ 201-\$ 250$ & ">8" \\
\hline 1 & 3 & 513.9 & 491.6 & 492.5 & $\mathrm{f}$ & 1994 & 1 & 0 & "Very Rarely" & $\$ 1-\$ 50$ & "2" \\
\hline 3 & 3 & 362.2 & 354.8 & 407 & $\mathrm{f}$ & 1990 & 1 & 1 & Never & $\$ 1-\$ 50$ & "6-8" \\
\hline 5 & 3 & 392.5 & 407.5 & 427.5 & $\mathrm{~m}$ & 1987 & 1 & 1 & $\begin{array}{l}\text { "A few times } \\
\text { a month" }\end{array}$ & $\$ 51-\$ 100$ & ">8" \\
\hline 11 & 3 & 464.6 & 494.9 & 498.75 & $\mathrm{f}$ & 1990 & 1 & 0 & "Very Rarely" & $\$ 1-\$ 50$ & "6-8" \\
\hline 13 & 3 & 208.75 & 211.5 & 194.75 & $\mathrm{f}$ & 1994 & 1 & 0 & "Very Rarely" & $\$ 1-\$ 50$ & "6-8" \\
\hline 27 & 3 & 212.75 & 189.75 & 218 & $\mathrm{~m}$ & 1994 & 1 & 0 & $\begin{array}{l}\text { "A few times } \\
\text { a month" }\end{array}$ & $\$ 1-\$ 50$ & ">8" \\
\hline 29 & 3 & 498.75 & 577.4 & 597.9 & $\mathrm{f}$ & 1994 & 1 & 0 & $\begin{array}{l}\text { "A few times } \\
\text { a month" }\end{array}$ & $\$ 101-\$ 150$ & "6-8" \\
\hline 31 & 3 & 492.5 & 490 & 492.5 & $\mathrm{f}$ & 1994 & 1 & 0 & "Very Rarely" & $\$ 1-\$ 50$ & "4-6" \\
\hline 33 & 3 & 332.75 & 296.75 & 325.35 & $\mathrm{f}$ & 1993 & 1 & 0 & "Very Rarely" & $\$ 1-\$ 50$ & "6-8" \\
\hline 35 & 3 & 284.8 & 371.95 & 286.6 & $\mathrm{f}$ & 1994 & 1 & 0 & "Very Rarely" & $\$ 1-\$ 50$ & "2-4" \\
\hline 37 & 3 & 277.5 & 290 & 295 & $\mathrm{f}$ & 1994 & 1 & 0 & "Very Rarely" & $\$ 1-\$ 50$ & ">8" \\
\hline 39 & 3 & 401.25 & 465 & 457.5 & $\mathrm{~m}$ & 1992 & 1 & 1 & $\begin{array}{l}\text { "Once a } \\
\text { month" }\end{array}$ & $\$ 51-\$ 100$ & "4-6" \\
\hline
\end{tabular}




\begin{tabular}{|c|c|c|c|c|c|c|c|c|c|c|c|}
\hline 41 & 3 & 338.2 & 338.2 & 391.5 & $\mathrm{f}$ & 1994 & 0 & 0 & Never & $\$ 0$ & "2" \\
\hline 43 & 3 & 160.85 & 160.85 & 165.35 & $\mathrm{f}$ & 1993 & 1 & 0 & $\begin{array}{l}\text { "Once a } \\
\text { month" }\end{array}$ & $\$ 1-\$ 50$ & ">8" \\
\hline 45 & 3 & 267.5 & 271.25 & 282.5 & $\mathrm{f}$ & 1994 & 1 & 0 & $\begin{array}{l}\text { "Once a } \\
\text { month" }\end{array}$ & $\$ 1-\$ 50$ & ">8" \\
\hline 47 & 3 & 332.5 & 318 & 325 & $\mathrm{~m}$ & 1994 & 1 & 0 & "Very Rarely" & $\$ 101-\$ 150$ & ">8" \\
\hline 49 & 3 & 307.5 & 272.5 & 300 & $\mathrm{f}$ & 1994 & 1 & 0 & "Very Rarely" & "Over \$300" & "6-8" \\
\hline 51 & 3 & 317.4 & 336.65 & 326.4 & $\mathrm{~m}$ & 1994 & 1 & 0 & $\begin{array}{l}\text { "Once a } \\
\text { month" }\end{array}$ & $\$ 51-\$ 100$ & ">8" \\
\hline 53 & 3 & 282.5 & 282 & 303 & $\mathrm{~m}$ & 1993 & 1 & 0 & $\begin{array}{l}\text { "A few times } \\
\text { a month" }\end{array}$ & $\$ 101-\$ 150$ & ">8" \\
\hline 55 & 3 & 181.25 & 189.5 & 175.5 & $\mathrm{~m}$ & 1991 & 1 & 0 & $\begin{array}{l}\text { "A few times } \\
\text { a month" }\end{array}$ & $\$ 101-\$ 150$ & "4-6" \\
\hline 59 & 3 & 364 & 388.75 & 413.95 & $\mathrm{f}$ & 1993 & 1 & 0 & "Very Rarely" & $\$ 0$ & "4-6" \\
\hline 61 & 3 & 309.25 & 323.75 & 320.75 & $\mathrm{~m}$ & 1993 & 1 & 0 & $\begin{array}{l}\text { "Once a } \\
\text { month" }\end{array}$ & $\$ 1-\$ 50$ & ">8" \\
\hline 63 & 3 & 254.85 & 234.45 & 259.5 & $\mathrm{~m}$ & 1994 & 1 & 0 & $\begin{array}{l}\text { "Once a } \\
\text { month" }\end{array}$ & $\$ 51-\$ 100$ & ">8" \\
\hline 65 & 3 & 328.4 & 359.1 & 335 & $\mathrm{f}$ & 1994 & 1 & 0 & $\begin{array}{l}\text { "A few times } \\
\text { a month" }\end{array}$ & $\$ 101-\$ 150$ & ">8" \\
\hline 67 & 3 & 571.65 & 551.55 & 540.15 & $\mathrm{f}$ & 1994 & 1 & 0 & "Very Rarely" & $\$ 51-\$ 100$ & ">8" \\
\hline 69 & 3 & 209 & 206.75 & 221 & $\mathrm{~m}$ & 1993 & 1 & 0 & $\begin{array}{l}\text { "Once a } \\
\text { month" }\end{array}$ & $\$ 151-\$ 200$ & "6-8" \\
\hline 71 & 3 & 234.5 & 230.5 & 252 & $\mathrm{f}$ & 1993 & 1 & 0 & $\begin{array}{l}\text { "Once a } \\
\text { month" }\end{array}$ & $\$ 101-\$ 150$ & "4-6" \\
\hline 73 & 3 & 134.75 & 130.45 & 135.2 & $\mathrm{f}$ & 1993 & 1 & 1 & $\begin{array}{l}\text { "Once a } \\
\text { month" }\end{array}$ & $\$ 51-\$ 100$ & "6-8" \\
\hline 75 & 3 & 205.5 & 211 & 227.75 & $\mathrm{f}$ & 1993 & 1 & 0 & $\begin{array}{l}\text { "Once a } \\
\text { month" }\end{array}$ & $\$ 51-\$ 100$ & "2-4" \\
\hline 77 & 3 & 237.5 & 262.5 & 247.5 & $\mathrm{~m}$ & 1994 & 0 & 1 & $\begin{array}{l}\text { "A few times } \\
\text { a month" }\end{array}$ & "Over \$300" & ">8" \\
\hline 79 & 3 & 535 & 525 & 520 & $\mathrm{f}$ & 1993 & 1 & 0 & "Very Rarely" & $\$ 1-\$ 50$ & ">8" \\
\hline 81 & 3 & 285 & 285 & 282.5 & $\mathrm{f}$ & 1994 & 1 & 0 & $\begin{array}{l}\text { "Once a } \\
\text { month" }\end{array}$ & $\$ 1-\$ 50$ & ">8" \\
\hline 83 & 3 & 244.85 & 214.9 & 242.3 & $\mathrm{f}$ & 1993 & 1 & 0 & $\begin{array}{l}\text { "Once a } \\
\text { month" }\end{array}$ & $\$ 51-\$ 100$ & "4-6" \\
\hline 85 & 3 & 236.5 & 263 & 246 & $\mathrm{~m}$ & 1994 & 1 & 0 & "Very Rarely" & $\$ 1-\$ 50$ & "2-4" \\
\hline 87 & 3 & 565 & 595 & 627.5 & $\mathrm{f}$ & 1994 & 1 & 0 & $\begin{array}{l}\text { "Once a } \\
\text { month" }\end{array}$ & $\$ 1-\$ 50$ & "4-6" \\
\hline 89 & 3 & 231.7 & 240.1 & 223.75 & $\mathrm{~m}$ & 1994 & 1 & 0 & $\begin{array}{l}\text { "A few times } \\
\text { a month" }\end{array}$ & $\$ 101-\$ 150$ & ">8" \\
\hline 91 & 3 & 392.5 & 368.5 & 367 & $\mathrm{f}$ & 1994 & 1 & 0 & $\begin{array}{l}\text { "A few times } \\
\text { a month" }\end{array}$ & $\$ 1-\$ 50$ & ">8" \\
\hline 93 & 3 & 263.75 & 265.75 & 288 & $\mathrm{~m}$ & 1994 & 1 & 0 & $\begin{array}{l}\text { "Once a } \\
\text { month" }\end{array}$ & $\$ 101-\$ 150$ & ">8" \\
\hline 95 & 3 & 532.5 & 570 & 527.5 & $\mathrm{~m}$ & 1993 & 1 & 0 & "Very Rarely" & $\$ 1-\$ 50$ & ">8" \\
\hline 97 & 3 & 342.7 & 337.25 & 354.45 & $\mathrm{~m}$ & 1993 & 1 & 0 & "Very Rarely" & $\$ 1-\$ 50$ & ">8" \\
\hline 99 & 3 & 243 & 240 & 234.25 & $\mathrm{f}$ & 1991 & 0 & 0 & Never & $\$ 0$ & "4-6" \\
\hline 101 & 3 & 288.25 & 291 & 294.25 & $\mathrm{f}$ & 1994 & 1 & 0 & "Very Rarely" & $\$ 1-\$ 50$ & "4-6" \\
\hline 103 & 3 & 356 & 350 & 359.5 & $\mathrm{~m}$ & 1994 & 1 & 0 & "Very Rarely" & $\$ 0$ & "2-4" \\
\hline 105 & 3 & 522.4 & 477.4 & 498.85 & $\mathrm{f}$ & 1994 & 1 & 0 & "Very Rarely" & $\$ 1-\$ 50$ & ">8" \\
\hline 107 & 3 & 436.25 & 440 & 436.25 & $\mathrm{~m}$ & 1994 & 1 & 0 & $\begin{array}{l}\text { "A few times } \\
\text { a month" }\end{array}$ & $\$ 151-\$ 200$ & "6-8" \\
\hline 109 & 3 & 411.5 & 429.5 & 439.5 & $\mathrm{f}$ & 1994 & 1 & 0 & "Very Rarely" & $\$ 1-\$ 50$ & "6-8" \\
\hline 111 & 3 & 333 & 327.5 & 334 & $\mathrm{f}$ & 1993 & 1 & 0 & "Very Rarely" & $\$ 1-\$ 50$ & ">8" \\
\hline
\end{tabular}




\begin{tabular}{|l|l|l|l|l|l|l|l|l|l|l|l|}
\hline 113 & 3 & 290.25 & 282 & 300.25 & $\mathrm{f}$ & 1994 & 1 & 0 & $\begin{array}{l}\text { "A few times } \\
\text { a month" }\end{array}$ & $\$ 101-\$ 150$ & $" 6-8 "$ \\
\hline 115 & 3 & 377.5 & 382.5 & 377.5 & $\mathrm{~m}$ & 1992 & 1 & 0 & "Very Rarely" & $\$ 1-\$ 50$ & $">8 "$ \\
\hline 119 & 3 & 216.45 & 162.9 & 176.1 & $\mathrm{~m}$ & 1994 & 1 & 0 & $\begin{array}{l}\text { "A few times } \\
\text { a month" }\end{array}$ & $\$ 101-\$ 150$ & $" 6-8 "$ \\
\hline 121 & 3 & 255.75 & 254 & 252.5 & $\mathrm{~m}$ & 1993 & 1 & 0 & $\begin{array}{l}\text { "A few times } \\
\text { a month" }\end{array}$ & $\$ 1-\$ 50$ & $">8 "$ \\
\hline 123 & 3 & 277.75 & 258 & 321 & $\mathrm{f}$ & 1994 & 1 & 0 & "Very Rarely" & $\$ 51-\$ 100$ & $" 6-8 "$ \\
\hline 125 & 3 & 379.75 & 361.75 & 302.25 & $\mathrm{f}$ & 1990 & 1 & 0 & "Very Rarely" & $\$ 1-\$ 50$ & $" 6-8 "$ \\
\hline
\end{tabular}




\section{Appendix G \\ San José State University Institutional Review Board Approval Letter}

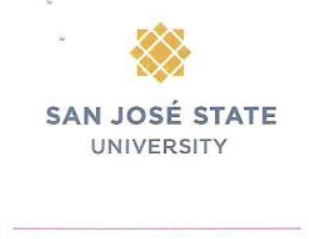

Division of Academic Affairs

Associate Vice President Graduate Studies \& Research

www.ssu.edu/gradstudies

One Washington Square San José, California 95192-0025 Voice: $408-924-2427$ Fax: 408-924-2612

www.sjsu.edu

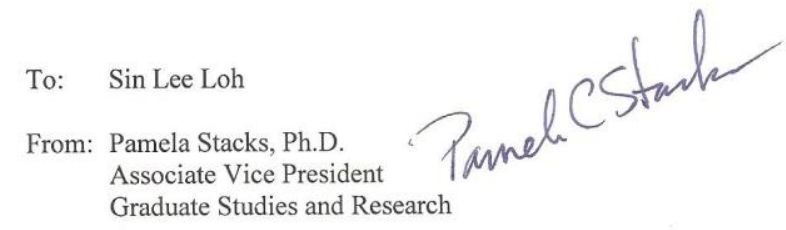

Date: February 22, 2013

The Human Subjects-Institutional Review Board has registered your study entitled:

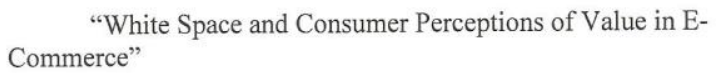

"White Space and Consumer Perceptions of Value in ECommerce"

This registration, which provides exempt status under Exemption Category 2, of SJSU Policy S08-7, is contingent upon the subjects participating in your research project being appropriately protected from risk. This includes the protection of the confidentiality of the subjects' identity when they participate in your research project, and with regard to all data that may be collected from the subjects. The approval includes continued monitoring of your research by the Board to assure that the subjects are being adequately and properly protected from such risks. If at any time a subject becomes injured or complains of injury, you must notify Dr. Pamela Stacks, Ph.D. immediately. Injury includes but is not limited to bodily harm, psychological trauma, and release of potentially damaging personal information. This approval for the human subject's portion of your project is in effect for one year, and data collection beyond February 22, 2014 requires an extension request.

Please also be advised that all subjects need to be fully informed and aware that their participation in your research project is voluntary, and that he or she may withdraw from the project at any time. Further, a subject's participation, refusal to participate, or withdrawal will not affect any services that the subject is receiving or will receive at the institution in which the research is being conducted.

If you have any questions, please contact me at (408) 924-2427.

Protocol \#: S1302038

cc. Sean Laraway

0120

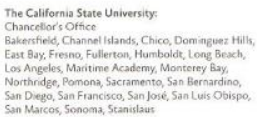

